\title{
WestVirginiaUniversity
}

THE RESEARCH REPOSITORY @ WVU

Graduate Theses, Dissertations, and Problem Reports

2017

\section{Effects of Chronic Electronic Cigarette Use on Glucose Metabolism}

Hannah Hoskinson

Follow this and additional works at: https://researchrepository.wvu.edu/etd

\section{Recommended Citation}

Hoskinson, Hannah, "Effects of Chronic Electronic Cigarette Use on Glucose Metabolism" (2017). Graduate Theses, Dissertations, and Problem Reports. 5823.

https://researchrepository.wvu.edu/etd/5823

This Thesis is protected by copyright and/or related rights. It has been brought to you by the The Research Repository @ WVU with permission from the rights-holder(s). You are free to use this Thesis in any way that is permitted by the copyright and related rights legislation that applies to your use. For other uses you must obtain permission from the rights-holder(s) directly, unless additional rights are indicated by a Creative Commons license in the record and/ or on the work itself. This Thesis has been accepted for inclusion in WVU Graduate Theses, Dissertations, and Problem Reports collection by an authorized administrator of The Research Repository @ WVU. For more information, please contact researchrepository@mail.wvu.edu. 


\title{
Effects of Chronic Electronic Cigarette Use on Glucose Metabolism
}

\author{
Hannah Hoskinson, B.S.
}

Thesis submitted to the School of Medicine, Division of Exercise Physiology at West Virginia University in partial fulfillment of the requirements for the degree of Master of Science in Exercise Physiology

\author{
Randy Bryner, Ed.D., Chair \\ Mark Olfert, Ph.D., \\ Stanley Hileman, Ph.D.
}

Division of Exercise Physiology

Morgantown, West Virginia 2017

Keywords: Electronic cigarette, E-cig, glucose, glucose metabolism

Copyright 2017 Hannah Hoskinson 


\title{
ABSTRACT
}

\section{Effects of Chronic Electronic Cigarette Use on Glucose Metabolism}

\author{
Hannah Hoskinson
}

Traditional cigarette usage has been linked to a number of nefarious metabolic effects, including insulin resistance; however, the effects of electronic cigarettes (E-cigs) are not currently known. Advertised as a safe alternative for traditional tobacco cigarettes, E-cigs still contain some of the same harmful chemicals as tobacco cigarettes. Through this study, we hope to gain perspective on whether e-cigs play into the development of altered glucose homeostasis. C57BL/6 mice were divided between E-cig $(n=15)$ and control $(n=15)$ groups and exposed to either cappuccino flavored E-cig vapor or filtered air for $4 \mathrm{~h} / \mathrm{d}, 5 \mathrm{~d} / \mathrm{wk}$ for 8 months. Fasting blood glucose (FBG) and glucose tolerance were observed after 6 months of exposure. Glucose was administered either orally or IP at $2 \mathrm{~g}$ glucose $/ \mathrm{kg}$ body mass. Following an overnight fast, an oral glucose tolerance test (OGTT) was performed prior to E-cig exposure; on a separate day another OGT was performed immediately after a 4-hour exposure period. In addition, an intraperitoneal glucose tolerance test (IPGTT) was performed immediately after a 4-hour exposure period in a subset of mice $(\mathrm{N}=4)$.

At the conclusion of 8 months of exposure, pancreas tissue was harvested and assessed in a subset of mice $(\mathrm{n}=6)$. Total body mass was similar between E-cig and air exposed groups at six months (E-cig: $28.7 \pm 1.1 \mathrm{~g}$ vs Control: $28.8 \pm 1.45 \mathrm{~g}$ ) and eight months (E-cig: $29.5 \pm 1.62 \mathrm{~g}$ vs Control: $28.9 \pm 1.06 \mathrm{~g}$ ). FBG prior to E-cig exposure tended to be higher in E-cig vs control mice $(\mathrm{p}=.13)$, while glucose following exposure were increased in the E-cig group $(143.8 \pm 6 \mathrm{mg} / \mathrm{dL}$ vs. $118.8 \pm 8 \mathrm{mg} / \mathrm{dL}, \mathrm{p}=0.05)$. During the IPGTT, E-cig animals presented with a higher peak blood glucose $(225 \pm 7 \mathrm{mg} / \mathrm{dL}$ vs. $180 \pm 15 \mathrm{mg} / \mathrm{dL}, \mathrm{p}=0.03)$, as well as a higher total area under the curve (AUC) than controls (18228 \pm 742 vs $15069 \pm 667$ respectively, $p=0.02)$. E-cig animals did not have a different $\beta$-cell density, insulin positive area, or number of SIRT1(+) nuclei. However, SIRT1 density (determined by number of SIRT1 $(+)$ nuclei/islet area) was lower in E-cig mice versus control (E-cig: $2.8 \mathrm{E}-4 \pm 5.0 \mathrm{E}-5$ nuclei $/ \mu \mathrm{m}$ vs Controls: $4.4 \mathrm{E}-4 \pm 5.0 \mathrm{E}-5$ nuclei $/ \mu \mathrm{m}$, $\mathrm{p}=0.05$ ). Total SIRT1 (E-cig: $1449 \pm 301 \mathrm{ng}$ vs Control: $1297 \pm 251 \mathrm{ng}$ ) and UCP2 (E-cig: $0.08 \pm$ 0.009 vs. Control: $0.10 \pm 0.01, \mathrm{AU}$ ) protein in the pancreas was not different between groups. In conclusion, chronic exposure to E-cig vapor resulted in modestly higher resting and stimulated blood glucose. Although total pancreatic SIRT1 protein levels were not affected, the density of SIRT1 positive $\beta$-cells was reduced in E-cig animals. Future research needs to determine if other pancreatic proteins and mechanisms are negatively affected because of E-cig exposure. 


\section{ABBREVIATIONS}

E-cig Electronic cigarette

T2DM Type 2 Diabetes Mellitus

UCP Uncoupling protein

GLUT4 Glucose transporter 4

PI3K Phosphoinositide 3-kinase

DHEA Dehydroepiandrosterone

ACTH Adrenocorticotropic hormone

HbA1C Hemoglobin a1C

HDL High density lipoprotein

VLDL Very-low density lipoprotein

HOMA-IR Homeostatic model assessment of insulin resistance 


\section{TABLE OF CONTENTS}

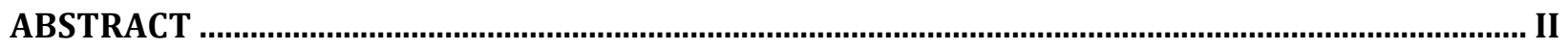

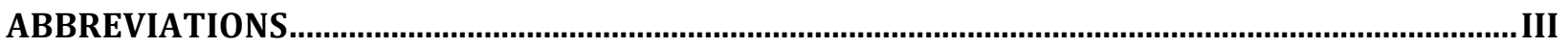

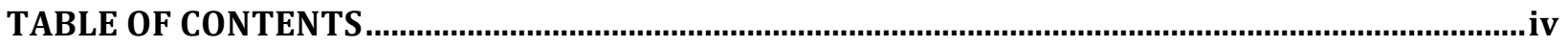

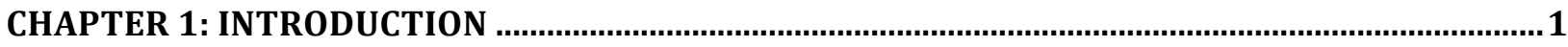

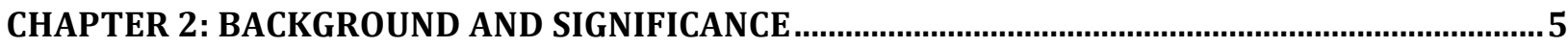

2.1 GLUCOSE REGULATION AND METABOLISM

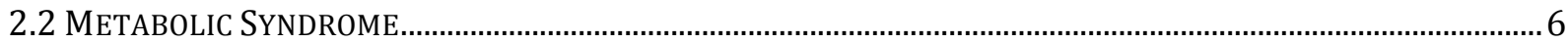

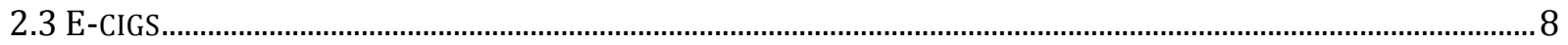

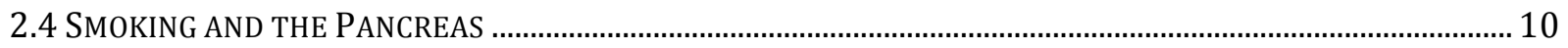

2.5 SIRT1

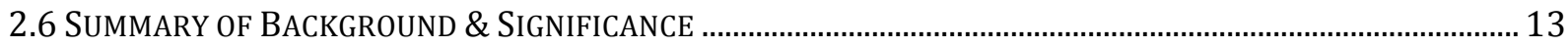

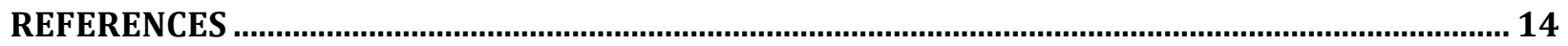

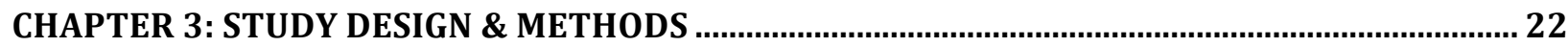

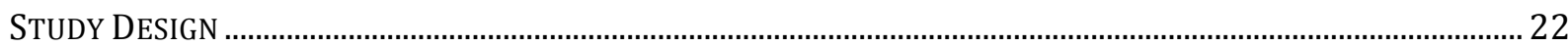

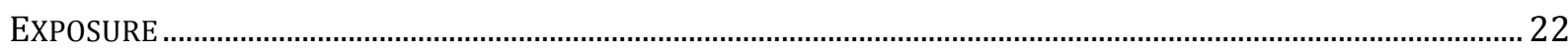

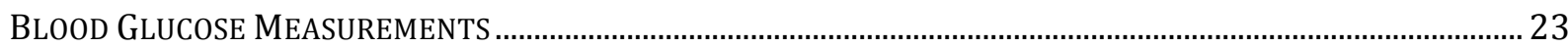

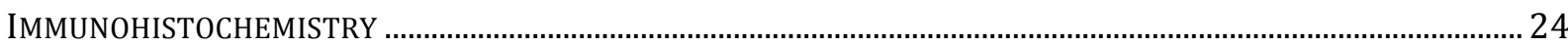

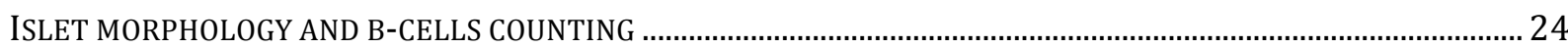

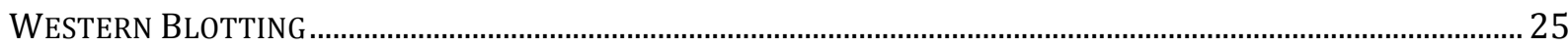

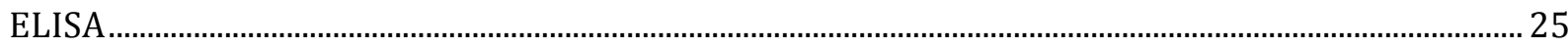

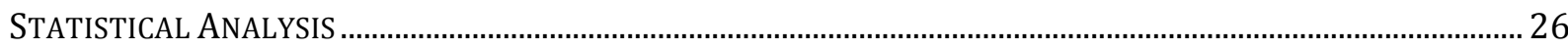

CHAPTER 4: RESULTS

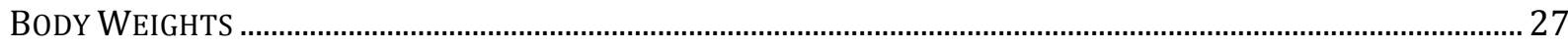

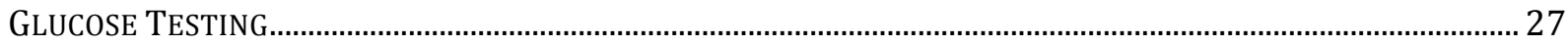

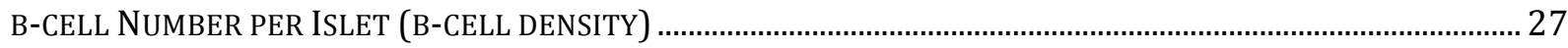

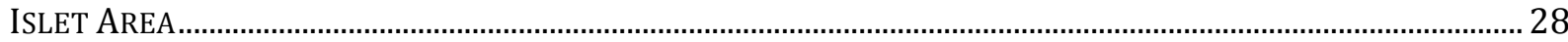

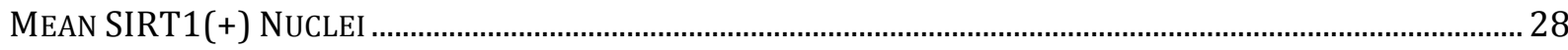

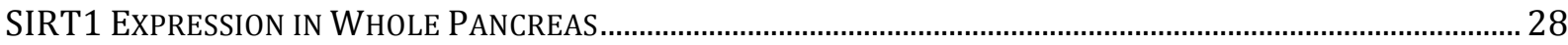

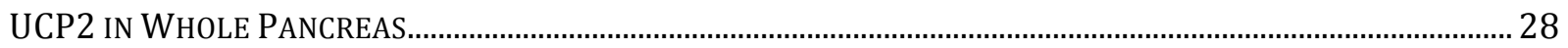

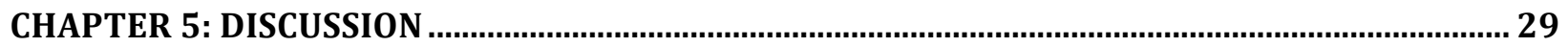

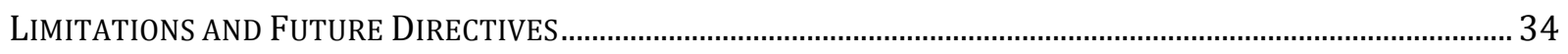

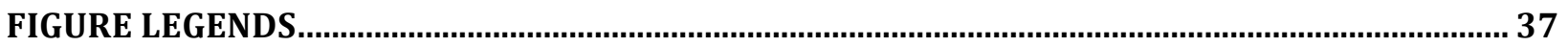

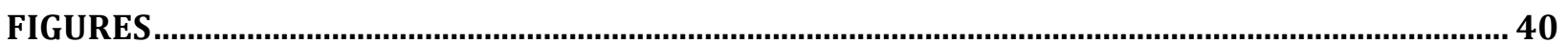

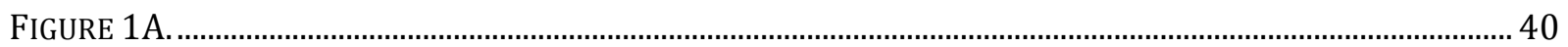

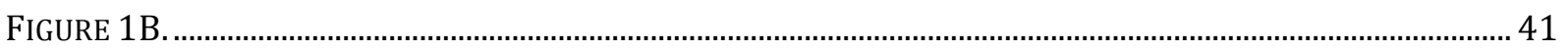

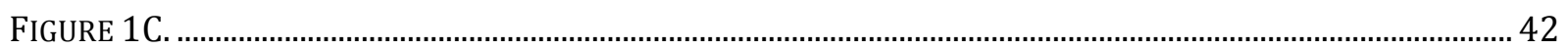

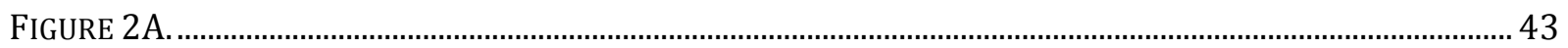

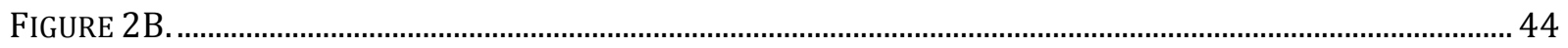

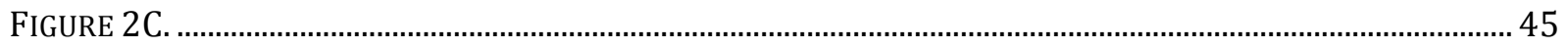

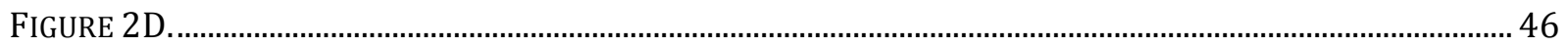

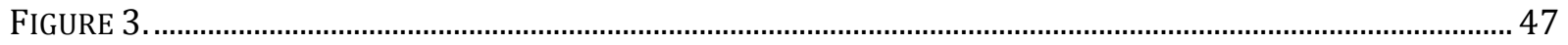

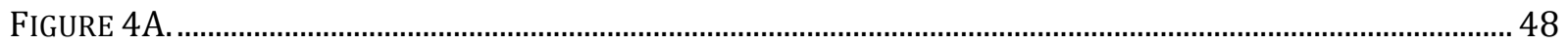

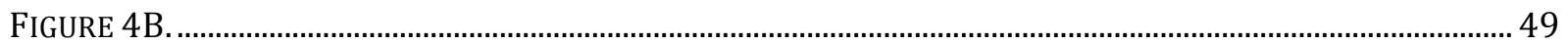




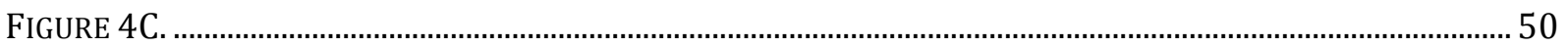

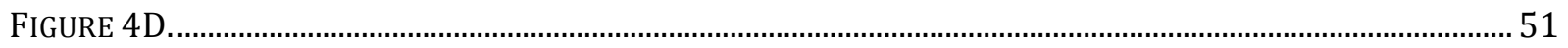

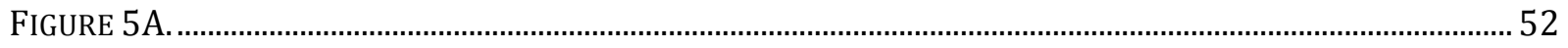

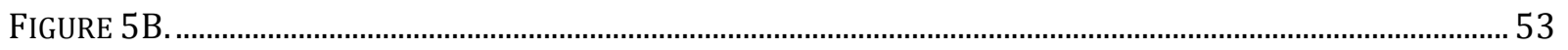

FIGURE 6A.

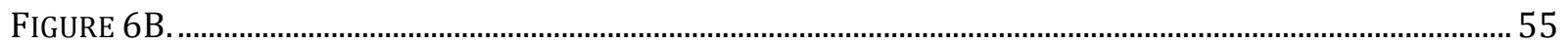

FIGURE 7A.

FIGURE 7B.

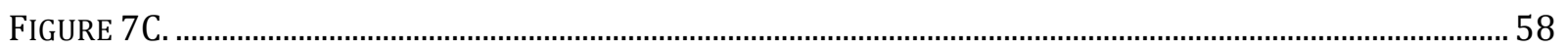

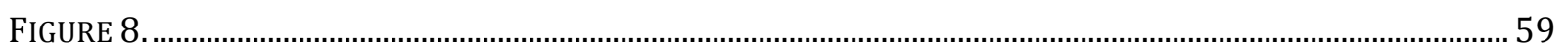

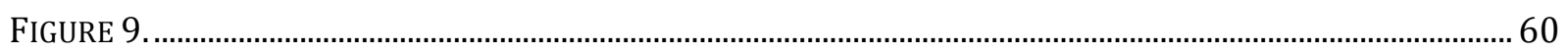




\section{CHAPTER 1: INTRODUCTION}

Approximately $17 \%$ of all Americans smoke cigarettes (CDC), and many of them are aware of the associated negative health effects. In their search for cessation help, one in five smokers turn to electronic cigarettes (E-cigs) (1). Smoking is often linked with metabolic syndrome, a state characterized by increased plasma lipids, obesity, hypertension, and insulin resistance; this pathology currently affects almost one-fourth of the world's population (2). One of the hallmark components of metabolic syndrome is impaired glucose tolerance as a result of impaired insulin secretion and/or impaired peripheral insulin sensitivity.

Traditional tobacco use through cigarettes is known to increase the risk of developing insulin resistance $(3,4,5,6)$ and type II diabetes $(\mathrm{T} 2 \mathrm{DM})(7,8,9,10,11,12)$, mostly due to nicotine's effects on the brain and organ systems. The two major hallmarks of these pathologies are an aberrant insulin production by the pancreas and an altered action of insulin in peripheral tissues $(29,31)$. In a healthy individual, a rise in blood glucose activates the islets of Langerhans within the $\beta$-cells of the pancreas to release insulin, a peptide hormone responsible for regulating the metabolism of circulating fats and carbohydrates (29). Some studies have linked nicotine directly to the dysfunction and destruction of pancreatic $\beta$-cells $(2,13)$. It has also been shown that smoking and its associated lifestyle causes a reduction in $\beta$-cell function $(10,14)$ as well as a greater demand on the $\beta$-cells to maintain blood glucose (9), due to increased stimulation of gluconeogenic pathways such as cathecholamines. When blood glucose maintenance places increased strain on the $\beta$-cells, this can overwhelm the cells and cause them to atrophy, a T2DM phenotype (9). A reduction in size of the $\beta$-cells is often followed by a reduction in overall function, leading to mishandling of carbohydrates and lipids causing hyperglycemia (15). 
Nicotine may also indirectly affect blood glucose levels via the alpha cells of the pancreas, which govern the secretion of glucagon. When nicotine enters the body, it stimulates nicotinic acetylcholine receptors in the brain and causes the release of catecholamines from the adrenal medulla $(16,17)$. The release of catecholamines is known to inhibit the release of insulin and to possibly stimulate the release of glucagon from the alpha cells of the pancreas (18). When alpha cells are stimulated to release glucagon into a normoglycemic individual, blood glucose concentrations can rise above what is normal and safe, thus creating a hyperglycemic state (19).

Uncoupling proteins (UCPs) have recently been identified as possible mediators in the development of obesity and obesity-related disease states (20). UCPs are located in the mitochondrial membrane of cells and are responsible for dissipating the proton gradient created by the process of generating ATP, thus uncoupling oxidative phosphorylation from the synthesis of energetic molecules (21). Though several different forms exist with specific targets and mechanisms, UCP2 has been identified in the pancreas and appears to play a role in insulin secretion (21).

When UCP2 uncouples the breakdown of glucose and the production of energy, it causes the available ATP/ADP ratio to decrease (18). In the $\beta$-cells, the presence of ATP induces insulin secretion by activating ATP-sensitive $\mathrm{K}+$ channels. The $\mathrm{K}+$ channels control the membrane potential of the cell, and when the channels close the membrane begins to depolarize which facilitates the influx of calcium, and ultimately increases the rate at which insulin is expelled via exocytosis (18). Since UCP2 decreases the amount of ATP present in the cell and that energy is then lost as heat, it could also indirectly decrease the amount of insulin released by the pancreas in response to a rise in plasma glucose (22). 
One of the proposed key regulators of pancreatic UCP2 is sirtuin 1 (SIRT1) (23), a $\mathrm{NAD}+$ dependent protein deacetylase that exists in both the nucleus and cytoplasm of $\beta$-cells (24). In the nucleus, SIRT1 deacetylates histone complexes to suppress transcription of certain genes. SIRT1 has also been proposed as one of the major players in whole-body insulin sensitivity, based on its dependence upon the NAD+/NADH or energy ratio within the cell (25). The presence of SIRT1 has been related to normal function and increased longevity of the $\beta$-cells (21), and increasing functional SIRT1 will decrease UCP2 (23) and inhibit $\beta$-cell apoptosis (26), thus preserving the cells' ability to release appropriate amounts of insulin in response to stimuli. If this mechanism is affected by damage incurred by nicotine either directly or indirectly through nicotine's role in hyperglycemia, it could further exacerbate the condition of increased blood glucose caused by nicotine.

SIRT1 has been found to function two ways in the pancreas: through UCP2 $(21,23,26)$, and through the Forkhead box $\mathrm{O} 1$ (FoxO1) pathway $(27,28)$. FoxO1 is a transcription factor thought to be essential for proper pancreatic differentiation, maturity, and overall function (27). When FoxO1 is inactivated, it allows insulin to have a more profound effect on suppressing glucose release from the liver (28), thus allowing insulin to reduce blood glucose levels to safe values before allowing hepatic glucose stores to compensate for the fall in glucose. SIRT1 is thought to inactivate FoxO1, which limits the amount of its transcription. FoxO1 plays a dynamic role in proliferation of pancreatic tissue and specifically in the formation of $\beta$-cells (98).

The primary objective of this study is to examine the effect of nicotine in combination with the other chemicals present in E-cig vapor on glucose metabolism and pancreatic health. The central hypothesis is that prolonged exposure to E-cig vapor will reduce $\beta$-cell number and pancreatic islet area and reduce SIRT1 and its dependent processes. Our rationale for conducting 
this study rests upon, in part, preliminary data demonstrating that animals exposed to 6-months of E-cig smoke had a significantly higher glucose profile compared with controls following an IP glucose challenge. This study will examine if this is related to altered pancreatic morphology and potential function. The proposed study looks to identify the consequences of E-cig exposure on glucose metabolism, and therefore determine the potential long-term effects of E-cigs on health. It is critical to provide more research on this topic in order to inform the general public on the possible negative effects these devices may have. The aim of this study is to:

Specific Aim 1: Examine the pancreatic $\beta$-cell number and islet area in mouse pancreas after being exposed to eight months of E-cig smoke.

The working hypothesis is that prolonged exposure to E-cig smoke will cause a reduction in both $\beta$-cell density and islet area compared with controls.

Specific Aim 2: Determine the effects of an eight-month E-cig exposure on pancreatic SIRT1 and its related proteins.

The working hypothesis is that prolonged exposure to E-cig smoke will cause a reduced number of SIRT1 positive $\beta$-cells, a reduced pancreatic SIRT1 protein content, and an increase in pancreatic UCP2 protein levels. 


\section{CHAPTER 2: BACKGROUND AND SIGNIFICANCE}

\subsection{Glucose Regulation and Metabolism}

In order to function properly, the body requires glucose levels to be within a narrow range. This is maintained by a multitude of factors and mechanisms, governed largely by hormones (103). Under low glucose conditions, the pancreas is stimulated to release glucagon and when blood glucose is high, the pancreas is stimulated to release insulin (103). Glucagon is a peptide hormone and is produced by the $\alpha$-cells of the pancreas and promotes gluconeogenesis and glycogenolysis to raise or maintain blood glucose (104). Insulin is also a peptide hormone produced by the $\beta$-cells within the Islet of Langerhans of the endocrine pancreas (104). It is responsible for facilitating the degradation of carbohydrates into energy sources (104).

When a meal is ingested, glucose is taken up into cells and broken down to derive ATP via glycolysis, thus increasing the intracellular ATP/ADP ratio (105). This increase in intracellular ATP causes ATP-sensitive potassium channels to close, which depolarizes the membrane of the cell and therefore opens voltage-gated calcium channels (18). The opening of these channels causes an influx of $\mathrm{Ca} 2+$ ions and stimulates the translocation of insulin vesicles to the cell membrane, thus allowing the release of insulin into the extracellular fluid of the pancreas where it is taken up into the bloodstream and delivered to extrapancreatic tissues (18).

Insulin has a variety of targets (the liver, brain, muscle, and adipose tissue to name a few) (46). Glucose transporter 4 (GLUT4) is insulin stimulated and is responsible for glucose entry into muscle cells. When insulin is present, phosphatidylinositol 3-kinase (PI3K) is recruited to the plasma membrane (53), which subsequently recruits Akt to the plasma membrane as well. The presence of this phosphorylated Akt at the membrane has been shown to facilitate the translocation of the glucose transporters $(54,55)$, as well as upregulating the efficacy of 
hexokinase (the first enzyme in glycolysis) $(56,57)$. Akt regulates not only the entry of glucose into the cells via glucose transporters but also the rate at which the glucose can be used by the cell to create energy (58).

Insulin also has profound effects on adipose tissue, promoting lipid synthesis and reducing the rate of lipid catabolism (46). In most tissues, insulin's efficacy depends on the presence of receptors. Consisting of two $\alpha$ - and two $\beta$-subunits, insulin binds to the $\alpha$-subunit to activate the intracellular tyrosine kinase (46). The $\beta$-subunits autophosphorylate each other and are responsible for inducing the event cascade intracellularly. Once the receptor is activated, recruitment of receptor substrates begins. These insulin receptor substrates (IRS) are a diverse family of proteins responsible for overseeing the cascade of signaling events in response to insulin release $(29,30)$.

Some glucose transporters, such as GLUT2, do not rely on insulin and are the primary glucose transportation device of pancreatic $\beta$-cells in mice and function similarly in humans (64). After developing persistent hyperglycemia, mouse GLUT2 has been shown to decrease substantially (65), limiting the ability of the pancreas to take up and therefore sense changes in concentration of glucose.

\subsection{Metabolic Syndrome}

Metabolic syndrome is an umbrella term for a cluster of risk factors predicting cardiovascular disease (CVD) and type II diabetes mellitus (T2DM), which include hypertriglyceridemia, hypercholesterolemia, hypertension, excessive central adiposity, and insulin resistance. In terms of glucose regulation, dyslipidemia and insulin insensitivity create the most poignant issues (31). Insulin resistance is a condition in which a normal concentration of insulin does not produce a matched effect in insulin action at the periphery (31). This blunted 
peripheral response stimulates the $\beta$-cells to release more insulin, causing hyperinsulinemia to overcome the sustained hyperglycemia. When this state is prolonged, both the target tissues and the $\beta$-cells become overwhelmed, causing the tissue's receptor density and function to decrease (32) and the $\beta$-cells to become damaged $(33,34)$. T2DM occurs in those organisms whose $\beta$-cells are unable to adequately compensate, resulting in sustained hyperglycemia (35).

Prolonged states of hyperglycemia such as those seen with the T2DM phenotype have been associated with an initial increase in mass of the $\beta$-cells as they attempt to compensate and continue regulating glucose and insulin levels (66). The $\beta$-cell mass is maintained or increased $(67,68)$ by islet neogenesis and $\beta$-cell hypertrophy and/or replication (66). Issues arise when the pancreas can no longer regulate glucose levels within a normal range and are marked by a reduced ability to release insulin based on glucose levels, or glucose-stimulated insulin secretion (GSIS) $(66,73)$. In addition to increases in $\beta$-cell mass, the $\beta$-cells can compensate by increasing in function $(69,70,71)$. Increased circulating glucose results in an upregulation of glycolysis, which will alter the ATP/ADP ratio, causing upregulation of the $\mathrm{K}+\mathrm{ATP}$-dependent pathway responsible for releasing insulin granules (72).

Dyslipidemia is characterized as increased low-density lipoprotein (LDL) (plasma cholesterol and/or triglycerides) and decreased high-density lipoprotein (HDL), and can be caused by genetic or environmental factors (36). Dyslipidemia often stems from excessive caloric intake from a diet rich in fats (40), but in conjunction with insulin resistance, the condition is worsened. Hepatic very low-density lipoprotein (VLDL) synthesis from hepatic stores is increased, which directly exacerbates the hyperlipidemic state (37). HDL and insulin have also been shown to have an inverse relationship $(37,38)$, so the hyperinsulinemic individual will have lower circulating HDL due to an uncompensated rate of degradation of apoA-I/HDL 
(39). Abnormal lipid profiles have been linked with numerous metabolic consequences, many of which decrease overall health and quality of life.

\subsection{E-cigs}

E-cigs, devices offer an alternative smoking experience by delivering nicotine, flavorings, and other additives. Their appeal is not only to those who smoke ( 1 in 5 smokers will turn to E-cigs as a smoking cessation tool) (1), but also as a gateway into smoking (41). Regardless of their target consumer, E-cig companies advertise their products as "safe" and containing "just vapor", but without strict FDA guidelines, ingredients are not regulated. E-liquid is generally composed of three basic components: a humectant (propylene glycol and/or vegetable glycerin), nicotine in varying concentrations, and flavorings comprised of different additives (78). These liquid ingredients are then passed through a heating element, which are vaporized and delivered to the smoker.

Propylene glycol (PG) is a chemical used widely in cosmetics, antifreeze, detergents, paints, and as an FDA-approved additive in food (42). Acute exposure to PG is a known irritant to the human airway $(43,44)$, facilitates infiltration of pro-inflammatory markers such as IL-6 (44), and is a known carcinogen (45). The other base chemical widely used in E-liquid is vegetable glycerin (VG), which also acts as a humectant, solvent, and sweetener. VG is nontoxic and used in foods and pharmaceuticals. Glycerin, also called glycerol, can enter either glycolysis or gluconeogenesis via glycerol kinase where it can be used to synthesize energetic material or contribute to glucose stores (94).

PG can be oxidized at relatively low temperatures $\left(127-227^{\circ} \mathrm{C}\right)$ to yield formaldehyde, acetaldehyde, and carbon dioxide and can form acetone via a dehydration reaction (74). Glycerol dehydration results in formation of acrolein (75), an electrophilic compound with a very high 
toxicity. When PG and glycerol reach high enough temperatures (as they often do within the Ecigs, due either to intentional heating to get more smoke or unintentionally through accidental overheating), they degrade to form these dangerous carbonyl compounds (76).

Nicotine is the first of the optional additives to E-liquid. Concentrations vary between 0$>50 \mathrm{mg} / \mathrm{mL}$, which is roughly equivalent to the nicotine content available in tobacco cigarettes (114). It has been seen that when nicotine levels decrease, smokers often compensate by smoking more often, essentially reaching the same nicotine levels (77). While this tendency is not only counterproductive to the concept of reducing nicotine intake, it also may inadvertently cause overheating of the E-cig device and result in the greater creation of harmful carbonyl compounds delivered to the user.

Flavorings are the final main component available in many E-liquids. Hundreds of brands and thousands of flavors currently exist (78), with many flavors seemingly marketed toward adolescents or those who may never otherwise used a nicotine delivery product before (79). Many of the additives used to make the flavors are the same as used by the food industry to enhance the flavors in food (79), but although these compounds have been deemed safe for ingestion, little to no evidence exists supporting their safety for inhalation. In fact, chronic exposure to aerosolized diacetyl, or 2,3-butanedione (used to give foods a butter flavor), has been proven to cause Bronchiolitis obliterans, or "popcorn lung" $(79,80)$. Evaluation of Eliquids has shown that diacetyl is present in numerous flavors, resulting in exposure over the limits set forth by OSHA $(81,82)$. In addition to being harmful to the pulmonary system, these chemical additives have also been shown to cause the secretion of pro-inflammatory cytokines and increase oxidative stress in lung tissue (83). 


\subsection{Smoking and the Pancreas}

Smoking has been linked with insulin resistance $(3,4,5,6)$ and altered lipid profiles $(60)$, as well as the development of $\operatorname{T2} \operatorname{DM}(7,8,9,10,11,12)$. The main and addictive ingredient in tobacco cigarettes is nicotine, which is also present in varying concentrations in E-cig liquids. Nicotine is rapidly absorbed in the alveoli of the lung and enters the bloodstream. When it reaches the brain, it binds to nicotinic cholinergic receptors (62) and begins a marked response in the hypothalamic-pituitary-adrenal (HPA) axis (16). In a dose dependent manner, the absorption of nicotine sparks the release of glucocorticoids and catecholamines, specifically adrenocorticotropic hormone (ACTH), cortisol, epinephrine, and dehydroepiandrosterone (DHEA) (16). The presence of glucocorticoids has been shown to directly inhibit the release of insulin (84) from $\beta$-cells while catecholamines stimulate the release of glucagon to elevate blood glucose (85) partially via the $\alpha$-cells. Both of these effects exacerbate the other, creating and propagating the hyperglycemic state. Both heavy and light smoking have been associated with changes in carbohydrate metabolism. HbA1c, which refers to glycated hemoglobin, has been long established as an accepted method of estimating average blood glucose over a period of weeks to months. Elevated levels have been seen in smokers (86), as well as a very high prevalence of impaired fasting glucose (86).

The literature on nicotine's effect on the pancreas is not all in agreement. Studies in rats injected with nicotine have found no differences in blood glucose, but did find that plasma insulin concentrations were significantly decreased as well as the homeostatic model assessment of insulin resistance (HOMA IR), which relates fasting glucose, insulin, and C-peptide concentrations (87). This supports the notion that nicotine increases insulin sensitivity in an acute manner. Long-term suppression of these cells may have a different effect. Studies have also shown that the insulin requirement for smokers is higher to maintain the same glucose reading as 
non-smokers (9) in exogenous insulin-dependent diabetic patients. Examination of post-smoking oral glucose tolerance tests in rats have also shown impairments, even when compared to a nonsmoking glucose tolerance test of the same individual (88).

Very few studies have examined the effect of E-cig vapor on glucose homeostasis, but there exists some evidence that E-cig vapor both with and without nicotine increases glycemia (89). The same study also recorded a significantly decreased hepatic glycogen breakdown in both nicotine-containing and non-nicotine containing E-cig vapors (89), leading to the postulation that these animals are calling upon glycogen stores to maintain an elevated blood glucose level.

In addition to acute effects on blood concentrations of hormones, smoking and nicotine have been shown to have negative effects on the pancreas itself. There is some evidence that the $\beta$-cells themselves have nicotine receptors (13). Extracted $\beta$-cells from rat and human pancreas were exposed to varying concentrations of nicotine and their ability to release insulin decreased (13). Morphological differences have been seen as well, including reduced $\beta$-cell mass (90), increased $\beta$-cell apoptosis (90), and lesions and significant markers of inflammation (91) in pancreas exposed to chronic nicotine. $\beta$-cell function was also found to be decreased following nicotine exposure in human subjects via the HOMA $\beta$-cell function assessment (formula for deriving $\beta$-cell functionality from insulin and glucose levels) (92).

\subsection{SIRT1}

One of the many regulating factors of physiological systems (and the pancreas specifically) is silent mating type information regulation 2 homolog, or SIRT1. The human SIRT proteins are orthologs to the family of yeast sirtuins and function to deacetylate proteins (NADdependent) thereby increasing longevity of the genetic material via gene silencing $(23,47)$. The 
SIRT family is thought to work through two basic mechanisms, UCP2 (23) and universal FoxO1 (95).

Since UCP2 uncouples oxidative phosphorylation from the synthesis of energetic molecules, it causes the available ATP/ADP ratio to decrease (18). Pancreatic $\beta$-cells rely almost exclusively on this ratio to induce insulin secretion via ATP-sensitive $\mathrm{K}+$ channels. Increased expression of UCP2 indirectly decreases the amount of insulin released in response to a rise in plasma glucose (22). It has been postulated that SIRT1 decreases UCP2 presence by binding directly to the UCP2 promoter in order to silence it (23), so when SIRT1 is present in acceptable levels it allows energy coupling to proceed as normal. Furthermore, reduction in UCP2 restores normal insulin secretion (23). When SIRT1 expression becomes impaired or decreased, UCP2 expression is allowed to increase, thus uncoupling oxidation from phosphorylation of ADP and disturbing the energetic state of the cell - and by extension, the insulin response. Mice with insulin resistance exhibited decreased SIRT1 protein levels in muscle compared to unimpaired controls (50) and decreased blood insulin levels (23). It has also been shown that increasing expression of SIRT1 can improve insulin sensitivity (50).

The other main component of the SIRT1 is the FoxO1 pathway. FoxO1 is inhibited by insulin via the Akt pathway (96) and changes in FoxO1 levels have been shown to have negative effects on insulin sensitivity (97). In the pancreas, FoxO1 is produced exclusively within the $\beta$ cells, and is thought to play a vital role in cell proliferation and formation of $\beta$-cells during growth as well as stress resistance (98). During formation of the pancreas, FoxO1 is widely produced in the epithelium of the pancreas (100). Mouse embryos lacking FoxO1 do not develop fully mature vasculature, so pancreas-specific FoxO1 deficiency in early development has not been able to be studied (101); however, FoxO1 has been identified as a negative regulator of 
differentiation in human fetal pancreas due to its inhibitory effects on crucial transcription factors such as NGN3 and NKX6-1 (98). During bouts of oxidative stress, FoxO1 is translocated into the nucleus of the $\beta$-cell, where it acts to restrict growth or further proliferation in order to prevent further oxidative damage to the cell (99). Global overexpression of FoxO1 leads to impaired glucose, insulin, and triglyceride levels when fasted but reduced glucose, insulin, and triglyceride levels when fed (52).

\subsection{Summary of Background \& Significance}

With prevalence of E-cig use on the rise, it is important to better understand the impacts it may have on overall health. Exposure to nicotine may result in any number of negative effects may occur not only to airways and blood vessels, but also to the body's ability to properly regulate glucose. In addition to nicotine, flavoring compounds also pose a threat to glucose homeostasis and could exacerbate or even induce hyperglycemia and dyslipidemia. These flavorings are neither listed nor considered a concern to the consumer when the constituents of their vaporized states are largely unknown. Dysfunction in glucose handling has become a national epidemic, and there exists a need to understand more fully what these devices are releasing and their metabolic consequences. A base body of knowledge must exist before these products can be readily advertised as a safe alternative, a body that is currently absent. 


\section{REFERENCES}

1. King, B. A., Alam, S., Promoff, G., Arrazola, R., \& Dube, S. R. (2013). Awareness and ever-use of electronic cigarettes among U.S. adults, 2010-2011. Nicotine and Tobacco Research, 15(9), 1623-1627. doi:10.1093/ntr/ntt013

2. Borowitz, J. L., \& Isom, G. E. (2008). Nicotine and type 2 diabetes. Toxicological Sciences : An Official Journal of the Society of Toxicology, 103(2), 225-7. doi: $10.1093 /$ toxsci/kfn050

3. CR, F. A. F. (1996). Acute effect of cigarette smoking on glucose tolerance and other cardiovascular risk factors. Diabetes Care, 19(2), 112-118.

4. Chiolero, A., Faeh, D., Paccaud, F., \& Cornuz, J. (2008). Consequences of smoking for body weight, body fat distribution, and insulin resistance. The American Journal of Clinical Nutrition, 801-809.

5. Ebersbach-Silva, P., Alves, T., Fonseca, A. T. S., Oliveira, M. A. do N., Machado, U. F., \& Seraphim, P. M. (2013). Cigarette smoke exposure severely reduces peripheral insulin sensitivity without changing GLUT4 expression in oxidative muscle of Wistar rats. Arquivos Brasileiros de Endocrinologia E Metabologia, 57(1), 19-26. Retrieved from http://www.ncbi.nlm.nih.gov/pubmed/23440095

6. Tatebe, J., \& Morita, T. (2011). Enhancement of TNF- $\alpha$ expression and inhibition of glucose uptake by nicotine in the presence of a free fatty acid in $\mathrm{C} 2 \mathrm{C} 12$ skeletal myocytes. Hormone and Metabolic Research, 43(1), 11-16. doi:10.1055/s-0030-1267996

7. Eliasson, B. (2003). Cigarette smoking and diabetes. Progress in Cardiovascular Diseases, 45(5), 405-413. doi:10.1053/pcad.2003.00103

8. Luo, J., Rossouw, J., Tong, E., Giovino, G. a, Lee, C. C., Chen, C., ... Margolis, K. L. (2013). Smoking and diabetes: does the increased risk ever go away? American Journal of Epidemiology, 178(6), 937-45. doi:10.1093/aje/kwt071

9. Madsbad, J., McNair, P., Christensen, M., Christiansen, C., Faber, K., Binder, C., Transbol, I. (1980). Influence of Smoking on Insulin Requirement and Metabolic Status of Diabetes Mellitus. Diabetes Care, 3(1), 41-43. doi:10.1111/j.10958649.2006.01157.x

10. Ostgren, C. J., Lindblad, U., Ranstam, J., Melander, A., Rastam, L., Skaraborg, H., \& Diabetes, P. (2000). Associations between smoking and beta-cell function in a nonhypertensive and non-diabetic population. Skaraborg Hypertension and Diabetes Project. Diabet Med, 17(6), 445-450. Retrieved from http://www.ncbi.nlm.nih.gov/pubmed/10975213

11. Tweed, J. O., Hsia, S. H., Lutfy, K., \& Friedman, T. C. (2012). The endocrine effects of nicotine and cigarette smoke. Trends in Endocrinology and Metabolism: TEM, 23(7), 334-42. doi:10.1016/j.tem.2012.03.006

12. Willi, C., Bodenmann, P., Ghali, W. a, Faris, P. D., \& Cornuz, J. (2014). Active Smoking and the Risk of Type 2 Diabetes. Clinician's Corner, 298(22).

13. Yoshikawa, H., Hellström-Lindahl, E., \& Grill, V. (2005). Evidence for functional nicotinic receptors on pancreatic beta cells. Metabolism: Clinical and Experimental, 54, 247-254. doi:10.1016/j.metabol.2004.08.020

14. M. Daniel, M. D. C. (2003). Association between smoking, insulin resistance and $\beta$-cell function in a North-western First Nation. Diabetes UK, 21, 188-193. doi:10.1046/j. 1464 
15. Zheng Z, Chen H,Li J,Li T, Zheng B, Zheng Y, Jin H, He Y, Gu Q, Xu X. Sirtuin 1mediated cellular metabolic memory of high glucose via the LKB1/AMPK/ROS pathway and therapeutic effects of metformin. Diabetes 2012; 61: 217-228 [PMID: 22124463 DOI: $10.2337 / \mathrm{db} 11-0416]$

16. Mendelson, J. H., Sholar, M. B., Goletiani, N., Siegel, A. J., \& Mello, N. K. (2005). Effects of low- and high-nicotine cigarette smoking on mood states and the HPA axis in men. Neuropsychopharmacology, 30(9), 1751-1763. doi:10.1038/sj.npp.1300753

17. Mishra, A., Chaturvedi, P., Datta, S., Sinukumar, S., Joshi, P., \& Garg, A. (2015). Harmful effects of nicotine. Indian Journal of Medical and Paediatric Oncology: Official Journal of Indian Society of Medical \& Paediatric Oncology, 36(1), 24-31. doi:10.4103/0971-5851.151771

18. Komatsu, M., Takei, M., Ishii, H., Sato, Y. (2013). Glucose-stimulated insulin secretion: A newer perspective. Journal of Diabetes Investigation. 4(6), 511-516.

19. Bearse MA Jr, Han Y, Schneck ME, Barez S, Jacobsen C, Adams AJ. Local multifocal oscillatory potential abnormalities in diabetes and early diabetic retinopathy. Invest Ophthalmol Vis Sci 2004;45:3259-65.

20. Brand, M., Esteves, T. (2005). Physiological functions of the mitochondrial uncoupling proteins UCP2 and UCP3. Cell Metabolism. Vol 2. Doi:10.1016/j.cmet.2005.06.002

21. Cao, y., Jiang, X., Ma, H., Wang, Y., Xue, P., Liu, Y. (2015). SIRT1 and insulin resistance. Journal of Diabetes and Its Complications. 30(1), 178-183.

22. Affourtit, C., Brand, M. (2008). On the role of uncoupling protein-2 in pancreatic beta cells. Biochemica et Biophysica Acta. 1777, 973-979.

23. Bordone, L., Motta, M. C., Picard, F., Robinson, A., Jhala, U. S., Apfeld, J., et al. (2006). Sirt1 regulates insulin secretion by repressing UCP2 in pancreatic beta cells. PLoS Biology, 4(2), e31 (0210-0220).

24. Chen, Y. R., Fang, S. R., Fu, Y. C., Zhou, X. H., Xu, M. Y., \& Xu, W. C. (2010). Calorie restriction on insulin resistance and expression of SIRT1 and SIRT4 in rats. Biochemistry and Cell Biology = Biochimie et Biologie Cellulaire, 88(4), 715-722.

25. 25. Liu Y, Dentin R, Chen D, Hedrick S, Ravnskjaer K, Schenk S, Milne J, Meyers DJ, Cole P, Yates J 3rd, Olefsky J, Guarente L, Montminy M., (2008). A fasting inducible switch modulates gluconeogenesis via activator/coactivator exchange. Nature. 456(7219):269-73.

26. Lafontaine-Lacasse, M., Dore, G., \& Picard, F. (2011). Hexosamines stimulate apoptosis by altering SIRT1 action and levels in rodent pancreatic beta-cells. The Journal of Endocrinology, 208(1), 41-49.

27. Kobayashi M, Kikuchi O, Tsutomu Sasaki, Hye-Jin Kim, Hiromi Yokota-Hashimoto, Yong-Soo Lee, Kosuke Amano, Tomoya Kitazumi, Vina Yanti Susanti, Yukari Ido Kitamura, Tadahiro Kitamura (2012). FoxO1 as a double-edged sword in the pancreas: analysis of pancreas- and $\beta$-cell-specific FoxO1 knockout mice. American Journal of Physiology: Endocrinology and Metabolism. 302(5): E603-13.

28. Kikuchi O, Kobayashi M, Amano K, Sasaki T, Kitasumi T, Kim HJ, Lee YS, KotoaHashimoto H, Kitamura Y, Kitamura T. (2012). FoxO1 Gain of Function in the Pancreas Causes Glucose Intolerance, Polycystic Pancreas, and Islet Hypervascularization. PLoS One. http://dx.doi.org/10.1371/journal.pone.0032249

29. White MF 2006. Regulating insulin signaling and $\beta$-cell function through IRS proteins. Can J Physiol Pharmacol 84: 725-737 
30. Shaw LM 2011. The insulin receptor substrate (IRS) proteins: At the intersection of metabolism and cancer. Cell Cycle 10: 1750-1756

31. DeFronzo RA, Tripathy D. Skeletal Muscle Insulin Resistance Is the Primary Defect in Type 2 Diabetes. Diabetes Care. 2009;32(Suppl 2):S157-S163. doi:10.2337/dc09-S302.

32. Del Prato S, Leonetti F, Simonson DC, Sheehan P, Matsuda M, DeFronzo RA: Effect of sustained physiologic hyperinsulinaemia and hyperglycaemia on insulin secretion and insulin sensitivity in man. Diabetologia 1994; 37: 1025- 1035

33. Abdul-Ghani MA, Tripathy D, DeFronzo RA: Contributions of beta-cell dysfunction and insulin resistance to the pathogenesis of impaired glucose tolerance and impaired fasting glucose. Diabetes Care 2006; 29: 1130- 1139

34. Gastaldelli A, Ferrannini E, Miyazaki Y, Matsuda M, DeFronzo RA: Beta-cell dysfunction and glucose intolerance: results from the San Antonio metabolism (SAM) study. Diabetologia 2004; 47: 31- 39

35. Tripathy D, Eriksson KF, Orho-Melander M, Fredriksson J, Ahlqvist G, Groop L: Parallel manifestation of insulin resistance and beta cell decompensation is compatible with a common defect in type 2 diabetes. Diabetologia 2004; 47: 782- 793

36. García-Giustiniani D, Stein R. Genetics of Dyslipidemia. Arquivos Brasileiros de Cardiologia. 2016;106(5):434-438. doi:10.5935/abc.20160074.

37. Brunzell JD, Porte D, Bierman EL: Abnormal lipoprotein lipase mediated plasma triglyceride removal in untreated diabetes mellitus associated with hypertriglyceridemia. Metabolism 28:901-907, 1979

38. Taskinen MR, Nikkila EA, Kuusi T: Lipoprotein lipase activity and serum lipoproteins in untreated type 2 (insulin-independent) diabetes associated with obesity. Diabetologia 22:46-50, 1982

39. Golay A, Zech L, Shi MZ, Chiou Y-AM, Reaven CM, Chen Y-DI: High density lipoprotein (HDL) metabolism in noninsulin-dependent diabetes mellitus: measurement of HDL turnover using tritiated HDL. j Clin Endocrinol Metab 65:512-18, 1987

40. .E. Bays, P.P. Toth, P.M. Kris-Etherton, et al. Obesity, adiposity, and dyslipidemia: a consensus statement from the National Lipid Association. J Clin Lipidol, 7 (2013), pp. 304-383

41. Corey et al., 2013 C. Corey, B. Wang, S.E. Johnson, B. Apelberg, C. Husten, B.A. King, et al. Electronic cigarette use among middle and high school students - United States, 2011-2012 MMWR Morbidity Mortal Wkly Rep, 62 (2013), pp. 729-730

42. Chemical prices and chemical industry trends; ICIS pricing: http:/www.icispricing. com/ (accessed Jan 23, 2015).

43. Wieslander G, Norback D, Lindgren T (2001) Experimental exposure to propylene glycol mist in aviation emergency training: acute ocular and respiratory effects. Occup Environ Med 58: 649-655

44. Wu Q, Jiang D, Minor M, Chu HW. Electronic Cigarette Liquid Increases Inflammation and Virus Infection in Primary Human Airway Epithelial Cells. Jeyaseelan S, ed. PLoS ONE. 2014;9(9):e108342. doi:10.1371/journal.pone.0108342.

45. Cressey D (2014) E-cigarettes affect cells. Nature 508: 159.

46. Wilcox G. Insulin and Insulin Resistance. Clinical Biochemist Reviews. 2005;26(2):1939.

47. G. Blander, L. Guarente, 2004. The Sir2 family of protein deacetylases. Annu. Rev. Biochem., 73 (2004), pp. 417-435 
48. J.T. Rodgers, C. Lerin, W. Haas, S.P. Gygi, B.M. Spiegelman, P. Puigserver, 2005. Nutrient control of glucose homeostasis through a complex of PGC-1alpha and SIRT1. Nature, 434 (2005), pp. 113-118

49. K.A. Moynihan, A.A. Grimm, M.M. Plueger, E. Bernal-Mizrachi, E. Ford, C. CrasMeneur, M.A. Permutt, S.-i. Imai. Increased dosage of mammalian Sir2 in pancreatic [beta] cells enhances glucose-stimulated insulin secretion in mice. Cell Metab., 2 (2005), pp. $105-117$

50. Sun C1, Zhang F, Ge X, Yan T, Chen X, Shi X, Zhai Q., 2007. SIRT1 improves insulin sensitivity under insulin-resistant conditions by repressing PTP1B. Cell Metab. 2007 Oct;6(4):307-19.

51. Meyer C, Stumvoll M, Nadkarni V, Dostou J, Mitrakou A, Gerich J. Abnormal renal and hepatic glucose metabolism in type 2 diabetes mellitus. Journal of Clinical Investigation. 1998;102(3):619-624.

52. Matsumoto M, Han S, Kitamura T, Accili D. Dual role of transcription factor FoxO1 in controlling hepatic insulin sensitivity and lipid metabolism. Journal of Clinical Investigation. 2006;116(9):2464-2472. doi:10.1172/JCI27047.

53. Van Obberghen, E., Baron, V., Delahaye, L., Emanuelli, B., Filippa, N., GiorgettiPeraldi, S., Lebrun, P., Mothe-Satney, I., Peraldi, P., Rocchi, S., Sawka-Verhelle, D., TartareDeckert, S., and Giudicelli, J. (2001) Eur. J. Clin. Investig. 31, 966-977

54. Kan, O., Baldwin, S. A., and Whetton, A. D. (1994) J. Exp. Med. 180, 917-921.

55. Hill, M. M., Clark, S. F., Tucker, D. F., Birnbaum, M. J., James, D. E., and Macaulay, S. L. (1999) Mol. Cell. Biol. 19, 7771-7781.

56. Gottlob, K., Majewski, N., Kennedy, S., Kandel, E., Robey, R. B., and Hay, N. (2001) Genes Dev. 15, 1406-1418.

57. Rathmell, J. C., Fox, C. J., Plas, D. R., Hammerman, P. S., Cinalli, R. M., and Thompson, C. B. (2003) Mol. Cell. Biol. 23, 7315-7328.

58. Riley JK1, Carayannopoulos MO, Wyman AH, Chi M, Moley KH, 2006.

Phosphatidylinositol 3-kinase activity is critical for glucose metabolism and embryo survival in murine blastocysts.

59. J Biol Chem. 2006 Mar 3;281(9):6010-9. Epub 2005 Nov 4.

60. Huiyun Liang, Walter F. Ward, 2006. PGC-1 $\alpha$ : a key regulator of energy metabolism. Advances in Physiology Education Dec 2006, 30 (4) 145-151;

DOI:10.1152/advan.00052.2006

61. Kong C, Nimmo L, Elatrozy T, Anyaoku V, Hughes C, Robinson S, Richmond W, Elkeles RS: Smoking is associated with increased hepatic lipase activity, insulin resistance, dyslipidaemia and early atherosclerosis in type 2 diabetes. Atherosclerosis 156: 373-378, 2001

62. Centers for Disease Control and Prevention. National Diabetes Statistics Report: Estimates of Diabetes and Its Burden in the United States, 2014. Atlanta, GA: US Department of Health and Human Services; 2014.

63. Benowitz NL, Hukkanen J, Jacob P. Nicotine Chemistry, Metabolism, Kinetics and Biomarkers. Handbook of experimental pharmacology. 2009;(192):29-60. doi:10.1007/978-3-540-69248-5_2.

64. Fransson L, Franzen S, Rosengren V, Wolbert P, Sjo“holm Å, Ortsa“ter H, 2013. b-cell adaptation in a mouse model of glucocorticoid-induced metabolic syndrome. $\mathrm{J}$ Endocrinol December 1, 2013 219231-241. 
65. Laura J. McCulloch,Martijn van de Bunt, Matthias Braun, Keith N. Frayn, Anne Clark, Anna L. Gloyn, 2011. GLUT2 (SLC2A2) is not the principal glucose transporter in human pancreatic beta cells: Implications for understanding genetic association signals at this locus. Molecular Genetics and Metabolism. Volume 104, Issue 4, December 2011, 648-65.

66. Jörns, A., Tiedge, M., Ziv, E. et al. Virchows Arch (2002) 440: 63. doi:10.1007/s004280100490

67. Gordon C. Weir, David Ross Laybutt, Hideaki Kaneto, Susan Bonner-Weir, Arun Sharma, 2001. -Cell Adaptation and Decompensation During the Progression of Diabetes. DIABETES, VOL. 50, SUPPLEMENT 1, Feb 2001. S154-159.

68. Steil G.M., et al. Adaptation of beta-cell mass to substrate oversupply: enhanced function with normal gene expression. Am. J. Physiol. Endocrinol. Metab. 2001;280:E788-E796.

69. Jetton T.L., et al. Mechanisms of compensatory beta-cell growth in insulin-resistant rats: roles of Akt kinase. Diabetes. 2005;54:2294-2304.

70. Liu Y.Q., Jetton T.L., Leahy J.L. Beta-cell adaptation to insulin resistance. Increased pyruvate carboxylase and malate-pyruvate shuttle activity in islets of nondiabetic Zucker fatty rats. . J. Biol. Chem. 2002;277:39163-39168.

71. Chen C., Hosokawa H., Bumbalo L.M., Leahy J.L. Mechanism of compensatory hyperinsulinemia in normoglycemic insulin-resistant spontaneously hypertensive rats. Augmented enzymatic activity of glucokinase in $\beta$-cells. J. Clin. Invest. 1994;94:399_ 404.

72. Van Citters G.W., et al. Elevated glucagon-like peptide-1-(7-36)-amide, but not glucose, associated with hyperinsulinemic compensation for fat feeding. J. Clin. Endocrinol. Metab. 2002;87:5191-5198.

73. Prentki M. New insights into pancreatic beta-cell metabolic signaling in insulin secretion. Eur. J. Endocrinol. 1996;134:272-286.

74. Prentki M, Nolan CJ. Islet $\beta$ cell failure in type 2 diabetes. Journal of Clinical Investigation. 2006;116(7):1802-1812. doi:10.1172/JCI29103.

75. Diaz E, Sad ME, Iglesia E. Homogeneous oxidation reactions of propanediols at low temperatures. ChemSusChem. 2010; 3:1063-70. doi: 10.1002/cssc.201000142 PMID: 20830723.

76. Nimlos MR, Blanksby SJ, Qian X, Himmel ME, Johnson DK. Mechanisms of glycerol dehydration. J. Phys Chem A. 2006; 110: 6145-56. doi: 10.1021/jp060597q PMID: 16671686.

77. Wang P, Chen W, Liao J, Matsuo T, Ito K, Fowles J, et al. (2017) A Device-Independent Evaluation of Carbonyl Emissions from Heated Electronic Cigarette Solvents. PLoS ONE 12(1): e0169811. doi:10.1371/journal.pone.0169811.

78. Hoffman D, Djordjevic MV, Brunnemann KD. Changes in cigarette design and composition over time and how they influence the yields of smoke constituents. J Smoking-Rel Disorder. 1995;6:9-23.

79. Zhu SH, Sun JY, Bonnevie E, et al. Four hundred and sixty brands of e-cigarettes and counting: implications for product regulation. Tob Control. 2014;23(suppl 3):iii3-iii9.

80. Barrington-Trimis JL, Samet JM, McConnell R. Flavorings in Electronic CigarettesAn Unrecognized Respiratory Health Hazard?. JAMA. 2014;312(23):2493-2494. doi:10.1001/jama.2014.14830. 
81. Kreiss K. Work-related spirometric restriction in flavoring manufacturing workers. Am J Ind Med. 2014;57(2):129-137.

82. Farsalinos KE, Kistler KA, Gillman G, Voudris V. Evaluation of electronic cigarette liquids and aerosol for the presence of selected inhalation toxins [published online September 1, 2014]. Nicotine Tob Res. doi: 10.1093/ntr/ntu176.

83. Allen JG, Flanigan SS, LeBlanc M, Vallarino J, MacNaughton P, Stewart Jh, Christiani DC. 2016. Flavoing chemicals in e-cigarettes: diacetyl, 2,3-pantanedione, and acetoin in a sample of 51 products, including fruit-, candy-, and cocktail-flavored e-cigarettes. Environ Health Perspect 124:733-739.

84. Lerner CA, Sundar IK, Yao H, Gerloff J, Ossip DJ, McIntosh S, et al. (2015) Vapors Produced by Electronic Cigarettes and E-Juices with Flavorings Induce Toxicity, Oxidative Stress, and Inflammatory Response in Lung Epithelial Cells and in Mouse Lung. PLoS ONE 10(2): e0116732. doi:10.1371/ journal.pone.0116732.

85. Delaunay F, Khan A, Cintra A, et al. Pancreatic beta cells are important targets for the diabetogenic effects of glucocorticoids. Journal of Clinical Investigation. 1997;100(8):2094-2098.

86. Ochs R S, Lardy H A (1983). Catecholamine Stimulation of Hepatic Gluconeogenesis at the Site between Pyruvate and Phosphoenolpyruvate. J. Biol. Chem. 1983, 258:99569962.

87. Hong JW, Ku CR, Noh JH, Ko KS, Rhee BD, Kim D-J. Association between SelfReported Smoking and Hemoglobin A1c in a Korean Population without Diabetes: The 2011-2012 Korean National Health and Nutrition Examination Survey. Fuhrman B, ed. PLoS ONE. 2015;10(5):e0126746. doi:10.1371/journal.pone.0126746.

88. Xu T-Y, Guo L-L, Wang P, et al. Chronic Exposure to Nicotine Enhances Insulin Sensitivity through $\alpha 7$ Nicotinic Acetylcholine Receptor-STAT3 Pathway. Chellappan SP, ed. PLoS ONE. 2012;7(12):e51217. doi:10.1371/journal.pone.0051217.

89. Frati AC1, Iniestra F, Ariza CR (1996). Acute effect of cigarette smoking on glucose tolerance and other cardiovascular risk factors. Diabetes Care. 1996 Feb;19(2):112-8.

90. Narges El.Golli, Houssem Dkhili, Yosra Dallagi, Dalila Rahali, Montassar Lasram, Ines Bini-Dhouib, Maryline Lebret, Jean-Philippe Rosa, Saloua El Fazaa, Monia Allal-El Asmi, Comparison between electronic cigarette refill liquid and nicotine on metabolic parameters in rats, Life Sciences, Volume 146, 2016, Pages 131-138, ISSN 0024-3205, http://dx.doi.org/10.1016/j.1fs.2015.12.049.

91. Jennifer E Bruin, Lisa D Kellenberger, Hertzel C Gerstein, Katherine M Morrison, Alison C Holloway (2007). Fetal and neonatal nicotine exposure and postnatal glucose homeostasis: identifying critical windows of exposure. J Endocrinol 194 (1) 171-178, doi: 10.1677/JOE-07-0050.

92. Wittel UA, Hopt UT, Batra SK. Cigarette smoke-induced pancreatic damageexperimental data. Langenbeck's archives of surgery / Deutsche Gesellschaft fur Chirurgie. 2008;393(4): 10.1007/s00423-007-0273-3. doi:10.1007/s00423-007-0273-3.

93. Ostgren CJ1, Lindblad U, Ranstam J, Melander A, Råstam L; Skaraborg Hypertension and Diabetes Project (2000). Associations between smoking and beta-cell function in a non-hypertensive and non-diabetic population. Skaraborg Hypertension and Diabetes Project. Diabet Med. 2000 Jun;17(6):445-50. 
94. Kalhan S. C., Mahajan S., Burkett E., Reshef L., Hanson R. W., 2001, Glyceroneogenesis and the souce of glycerol for hepatic triacylglycerol synthesis in human, J. Biol. Chem. , 276, 12928, 12931

95. Chae, H., \& Broxmeyer, H. E. (2010). SIRT1 Regulates PTEN/Akt/FOXO1 Pathway to Trigger ROS-Induced Apoptosis In Mouse Embryonic Stem Cells..Blood, 116(21), 1610. Accessed July 17, 2017. Retrieved from http://www.bloodjournal.org/content/116/21/1610.

96. Kitamura T, Nakae J, Kitamura Y, et al. The forkhead transcription factor Foxo1 links insulin signaling to $\mathrm{Pdx} 1$ regulation of pancreatic $\beta$ cell growth. The Journal of Clinical Investigation. 2002;110(12):1839-1847. doi:10.1172/JCI200216857.

97. Nakae J, et al. Regulation of insulin action and pancreatic beta-cell function by mutated alleles of the gene encoding forkhead transcription factor Foxol. Nat. Genet. 2002;32:245-253.

98. Al-Masri, M. et al. Effect of forkhead box O1 (FOXO1) on $\beta$ cell development in the human fetal pancreas. Diabetologia 53, 699-711 (2010).

99. Kawamori D, Kaneto H, Nakatani Y et al (2006) The forkhead transcription factor Foxo1 bridges the JNK pathway and the transcription factor Pdx-1 through its intracellular translocation. J Biol Chem 281:1091-1098.

100. Ahlgren U, Jonsson J, Edlund H (1996) The morphogenesis of the pancreatic mesenchyme is uncoupled from that of the pancreatic epithelium in IPF/PDX1-deficient mice. Development 122:1409-1416

101. Hosaka T, Biggs WH, Tieu D et al (2004) Disruption of Forkhead transcription factor (FOXO) family members in mice reveals their functional diversification. Proc Natl Acad Sci U S A 101:2975-2980

102. Holz GG 4th., Leech CA, Habener JF, (1995) Activation of a cAMP-regulated Ca(2+)signaling pathway in pancreatic beta-cells by the insulinotropic hormone glucagon-like peptide-1. J Biol Chem 270:17749-17757.

103. Halter, Jeffrey B., Kenneth Ward, W., Porte, Jr., Daniel, Best, James D., Pfeifer, Michael A. (1985/08/23)."Glucose regulation in non-insulin-dependent diabetes mellitus: Interaction between pancreatic islets and the liver." The American Journal of Medicine 79(2, Supplement 2): 6-12. http://hdl.handle.net/2027.42/25595

104. Gerich JE, Charles MA, Grodsky GM. Characterization of the Effects of Arginine and Glucose on Glucagon and Insulin Release from the Perfused Rat Pancreas. Journal of Clinical Investigation. 1974;54(4):833-841.

105. Gentian Buzi, Ufuk Topcu, John C. Doyle, "Quantitative nonlinear analysis of autocatalytic pathways with applications to glycolysis", American Control Conference (ACC) 2010, pp. 3592-3597, 2010, ISSN 2378-5861.

106. Weir GC ${ }^{1}$, Bonner-Weir S., (2004). Five stages of evolving beta-cell dysfunction during progression to diabetes. Diabetes. 2004 Dec;53 Suppl 3:S16-21.

107. Ramsey K, Mills K, Satoh A, Imai SI, (2007). Age-associated loss of Sirt1-mediated enhancement of glucose-stimulated insulin secretion in beta cell-specific Sirt1overexpressing (BESTO) mice. Aging Cell. Volume 7, Issue 1 February 2008. 78-88.

108. Narges El.Golli, Houssem Dkhili, Yosra Dallagi, Dalila Rahali, Montassar Lasram, Ines Bini-Dhouib, Maryline Lebret, Jean-Philippe Rosa, Saloua El Fazaa, Monia Allal-El Asmi, Comparison between electronic cigarette refill liquid and nicotine on metabolic 
parameters in rats, Life Sciences, Volume 146, 2016, Pages 131-138, ISSN 0024-3205, http://dx.doi.org/10.1016/j.1fs.2015.12.049.

109. Rolls ET. Brain mechanisms underlying flavour and appetite. Philosophical

Transactions of the Royal Society B: Biological Sciences. 2006;361(1471):1123-1136. doi:10.1098/rstb.2006.1852.

110. S. Prasad, R.K. Sajja, J.H. Park, P. Naik, M.A. Kaisar, L. Cucullo. Impact of cigarette smoke extract and hyperglycemic conditions on blood-brain barrier endothelial cells Fluids Barriers CNS, 12 (2015), p. 18.

111. Trimble ER, Renold AE (1981) Ventral and dorsal areas of rat pancreas: islet hormone content and secretion. Am J Physiol 240: E422-E427.

112. Trimble ER, Halban PA, Wollheim CB, Renold AE (1982) Functional differences between rat islets of ventral and dorsal pancreatic origin. J Clin Invest 69: 405-413.

113. Leclercq-Meyer V, Marchand J, Malaisse WJ (1985) Insulin and glucagon release from the ventral and dorsal parts of the perfused pancreas of the rat. Effects of glucose, arginine, glucagon and carbamylcholine. Horm Res 21: 19-32.

114. Malson JL, Sims K, Murty R, et al. Comparison of the nicotine content of tobacco used in bidis and conventional cigarettes. Tobacco Control 2001;10:181-183. 


\section{CHAPTER 3: STUDY DESIGN \& METHODS}

\section{Study Design}

Thirty female C57BL/6 mice aged 10 weeks were purchased from Jackson Laboratory (stock \#000664, Bar Harbor, ME) and randomly assigned into E-cig vapor (cappuccino-flavored, $18 \mathrm{mg} / \mathrm{ml}$ nicotine $)(\mathrm{N}=15)$ or filtered-air groups $(\mathrm{N}=15)$. After one week of adaptation to the new vivarium, baseline testing occurred and at 13-14 weeks of age, exposures began and lasted for 8 months. This protocol translates to smoking exposure from approximately 11-35 years of age assuming a total life span of 2 and 78 years for mice and men, respectively. Mice were group housed (4-5 animals, within exposure groups) in a temperature controlled $\left(22 \pm 4{ }^{\circ} \mathrm{C}\right.$, relative humidity $39 \pm 6 \%$ ) and pathogen free vivarium room with maintained $12 \mathrm{hr}$ light/dark cycle. Animals had ad libitum access to standard chow (18\% fat, $24 \%$ protein, $58 \%$ carbohydrates) and tap water except when otherwise noted. All procedures were approved by the WVU Institutional Animal Care and Use committee.

\section{Exposure}

Mice were exposed using identical $15.1 \mathrm{~L}$ whole body exposure chambers. E-cig vapor were gradually introduced during the first 8 weeks, beginning at one hour a day up to four hours a day. After each hour exposure, a washout period of 30 minutes of fresh air occurred, allowing the chamber to clear and mice to recover. This paradigm continued for 5 days/week for a total of 8 months. The E-cig device was a 3rd generation, tank-style, device purchased online (eGrip OLED, Joyetech, www.joyetech.com). The E-cig voltage was set to $4.8 \mathrm{~V}$, and was activated every 99 seconds for a 5-second duration, resulting in $\sim 38-39$ puffs each hour. The device was controlled by a custom-made artificial hand with an automatic switch attached to a timer. Vapor was generated and delivered to the respective chambers with rodent ventilators (Harvard 
Apparatus, Natick, MA) using $55 \mathrm{ml}$ tidal puff volume. Control mice received filtered (Carbon Cap 150, Whatman) from a central compressed air line.

\section{Blood Glucose Measurements}

After six months of exposure, a series of glucose tolerance tests were administered to a subset of mice. For test one, an oral glucose tolerance test (OGTT) was administered to animals following an 8 hour fast. Each animal was placed into its own cage and a fasting glucose reading was taken via nick in the tail vein using the Bayer Contour ${ }^{\circledR}$ glucometer and strips. A glucose bolus ( $2 \mathrm{~g} / \mathrm{kg}$ body mass) was then administered orally (via gelatin pellet containing a calculated amount of glucose). Mice were trained for two weeks to eat the glucose pellet and any mouse not completing the entire pellet in less than two minutes was excluded from the test. Blood glucose measurements were made at 15, 30, 60, 90, and 120 minutes post-ingestion. For test two, another OGTT was administered following an 8-hour fast. During this fast, mice were exposed to their normal 4-hour bout of vapor exposure. Following exposure, a fasting blood glucose reading was taken. A glucose bolus ( $2 \mathrm{~g} / \mathrm{kg}$ body mass) was then administered orally via gelatin pellet containing a calculated amount of glucose. Any mouse not completing the entire pellet in less than two minutes was excluded from the test. Subsequent glucose measurements were made at $15,30,60,90$, and 120 minutes post-ingestion. Because we noticed a trend for resting blood glucose to be higher in E-cig but had some difficulty getting all mice to reliably complete the glucose pellet after exposure, we chose to do a third glucose test. The third glucose test was an intraperitoneal glucose tolerance test (IPGTT) performed on a subset of mice post-vapor exposure. During this test, animals were fasted for eight hours and during the eight hours, the usual 4-hour bout of vapor exposure was carried out. Once the fast and smoke exposures were completed, each animal was individually housed and a fasting blood glucose reading was taken. 
Each mouse then received a bolus of glucose ( $2 \mathrm{~g}$ glucose $/ \mathrm{kg}$ body mass) via IP injection.

Subsequent glucose measurements were made at 15, 30, 60, 90, and 120 minutes post-injection.

\section{Immunohistochemistry}

Following 8-months of exposure, mice were euthanized and their pancreas tissue surgically removed. Fresh pancreas samples were mounted to cork and flash frozen using tissue embedding medium (OCT, Tissue Tek) and isopentane, then stored at $-80^{\circ} \mathrm{C}$ until used for IHC. Samples were sliced into $10 \mu \mathrm{m}$ thick sections using the Leica CM3050S cryostat at $-20^{\circ} \mathrm{C}$.

Sections were placed on glass slides and fixed in 4\% paraformaldehyde solution for 20 minutes. $0.2 \%$ Triton $\mathrm{X}-100$ was used to permeabilize the samples for 10 minutes, then the slides were blocked for 1 hour using goat serum. The primary antibodies used were Insulin (C27C9) Rabbit mAb \#3014 (Cell Signaling Technology) and SIRT1 (Cell Signaling Technology) and allowed to incubate overnight. Secondary antibodies were Alexafluor 555 IgG anti-rabbit and Alexafluor $488 \mathrm{IgG}$ anti-mouse (ThermoFisher and Fisher Scientific, respectively) and were incubated for 45 minutes. Slides were imaged using SPOT5.2 Advanced program. Images were analyzed using ImageJ.

\section{Islet morphology and $\beta$-cells counting}

15 islets islets from each animal ( $N=6$ animals for each group) were analyzed and $\beta$-cells counted individually from each islet using Image $J$. Image $J$ was also used to determine islet area in $\mu \mathrm{m}$. Individual nuclei were stained with DAPI and counted within the insulin positive area to determine $\beta$-cell number. Individual nuclei that expressed SIRT1 fluorescence were also counted and then normalized to islet area. 


\section{Western Blotting}

Pancreas was homogenized in Tris-buffered saline containing $50 \mathrm{mM}$ tris $/ \mathrm{HCl}, 150 \mathrm{mM}$ $\mathrm{NaCl}, 0.5 \%$ Triton X-100, Protease Inhibitor Tablet, and $\mathrm{H} 2 \mathrm{O}$ using the BeadMill system. Samples were then incubated for 40 minutes at $4^{\circ} \mathrm{C}$ with agitation, and centrifuged $(16,100 \mathrm{~g}, 20$ min, at $\left.4{ }^{\circ} \mathrm{C}\right)$. Samples were stored at $-80^{\circ} \mathrm{C}$.

Total protein was measured by Bradford assay (\#23236 Pierce Coomassie Plus Protein Assay Kit, Thermo Scientific, Rockford, IL) using bovine serum albumin standards.

Protein samples were electrophoresed with a 4-12\% Bis-Tris (Criterion XT Precast Gel 4$12 \%$ Bis-Tris,Hercules CA) gel and blotted onto a 0.45um nitrocellulose membrane (Pierce nitrocellulose membrane, Thermo Scientific, Rockford, IL). After blocking with 5\% fat-free milk, membranes were probed at $4^{\circ} \mathrm{C}$ for 24 hours by gentle rocking. Antibodies included: SIRT1 (Polyclonal rabbit IgG, Invitrogen: Rockford, IL, \#PA5-17232), UCP2 (Polyclonal rabbit IgG, Invitrogen: Rockford, IL, \#Pa5-36383), and FOXO1 (Monoclonal rabbit IgG, Invitrogen: Rockford, IL).

Chemiluminescent detection (Pierce ECL, Thermo Scientific, Rockford, IL) was carried out to visualize proteins and digitally imaged (G : BOX Gel imager, Syngene, Cambridge, UK) using Genesnap software (Ver. 7.01, Syngene, Cambridge, UK). $\beta$-tubulin was used as the housekeeping gene. Quantification of protein expression levels were carried out using NIH Image J Software (v1.62) and expressed as densitometric arbitrary units (AU).

\section{ELISA}

Whole pancreas SIRT1 was assessed via ELISA kit (Mouse SIRT1 ELISA Kit, Abcam ${ }^{\circledR}$, \#ab206983) according to the manufacturer instructions. Primary antibody incubation was performed for 3 hours and total protein content in each well was 350ug. 


\section{Statistical Analysis}

All data are represented as a mean $\pm \mathrm{SE}$, with a criterion of $P<.05$ for significance and were assessed using T-tests. r-ANOVA were used to analyze glucose tolerance curves. 


\section{CHAPTER 4: RESULTS}

\section{Body Weights}

The body weights were similar throughout the entire study and the growth curves

followed roughly the same shape (Figure 1A). They did not reach any statistical difference at the six-month time point (E:cig: $28.7 \pm 1.1 \mathrm{~g}$ vs Control: $28.8 \pm 1.5 \mathrm{~g}$ ) (Figure $1 \mathrm{~B}$ ) or the eight-month time point (E-cig: $29.5 \pm 1.6 \mathrm{~g}$ vs Control: $28.9 \pm 1.1 \mathrm{~g}$ ) (Figure 1C).

\section{Glucose Testing}

Although trending somewhat higher, resting blood glucose was not different without exposure (E-cig: $141 \pm 10 \mathrm{mg} / \mathrm{dL}$ vs Control: $123 \pm 6 \mathrm{mg} / \mathrm{dL}, \mathrm{p}=0.137)($ Figure $2 \mathrm{~A})$ or after a typical 4-hour exposure period (E-cig: $146 \pm 10 \mathrm{mg} / \mathrm{dL}$ vs Control: $142 \pm 10 \mathrm{mg} / \mathrm{dL}$ ) (Figure $2 \mathrm{~B}$ ). Following the OGTT, glucose curves were also not different without (Figure 2C) or after exposure (Figure 2D). Fasting blood glucose after exposure at six months exposure was significantly higher when assessed prior to IPGTT in the same selected group of E-cig mice $(144 \mathrm{mg} / \mathrm{dL})$ compared to control $(119 \mathrm{mg} / \mathrm{dL})(\mathrm{p}=0.05)$ (Figure 3). During the IPGTT, E-cig mice demonstrated an impaired capacity to clear glucose and presented with a higher glucose curve (Figure 4A). Figure 4B shows E-cigs IPGTT curve normalized for their higher baseline, with significance at 15 and 60 minutes $(\mathrm{P}=0.05)$. Additionally, peak glucose (at $15 \mathrm{~min}$ post IP injection) was significantly higher in E-cigs compared with control mice (225mg/dL vs $180 \mathrm{md} / \mathrm{dL}$ respectively, $\mathrm{p}<0.05$ ) (Figure $4 \mathrm{C}$ ). Total glucose (area under the curve) was also significantly greater in E-cig versus control mice $(p<0.05$, Figure 4D).

\section{$\beta$-cell Number per Islet ( $\beta$-cell density)}

The average number of $\beta$ cells per islet was examined by counting individual DAPI stained $\beta$-cells within the insulin stained positive area and used to calculate $\beta$-cell density. Mean $\beta$-cell number was not significantly different between groups (E-cig: $66 \pm 10$ vs Control: $68 \pm 10$ ) 
(Figure 5A). There was not a difference found between E-cig and control groups for $\beta$-cell density (E-cig: 2.1E-03 $\pm 2.0 \mathrm{E}-04$ vs Contol: 1.9E-03 $\pm 6.0 \mathrm{E}-04)$ (Figure 5B).

\section{Islet Area}

Islet area was determined by measuring insulin positive morphology, and also showed no difference between groups (E-cig: $62,200 \pm 12,733 \mu \mathrm{m}^{2}$ vs Control: $44,366 \pm 8,730 \mu \mathrm{m}^{2}$ ) (Figure 6A). Representative images of insulin and DAPI staining are located in Figure 6B.

\section{Mean SIRT1(+) Nuclei}

Mean SIRT1-positive nuclei were determined by counting the nuclei within the insulin positive area that were positive for SIRT1. A representation of this is shown in Figure 7A. No difference was seen in SIRT1(+) nuclei (E-cig: $14.7 \pm 2.7$ vs Control: $16.4 \pm 1.9$, Figure $7 \mathrm{~B})$, but when SIRT1 density was assessed (SIRT1(+) nuclei per islet area), E-cigs had a significantly decreased SIRT1 density (E-cig: 2.8E-04 \pm 5.0E-05 vs Control: 4.4E-04 \pm 5.0E-05 , p=0.05) (Figure 7C).

\section{SIRT1 Expression in Whole Pancreas}

SIRT1 expression in whole pancreas was assessed via ELISA kit (Abcam). No significant difference was seen between the two groups (E-cig: $1449 \pm 301 n g$ vs Control: $1297 \pm 251 \mathrm{ng}$ ) (Figure 8).

\section{UCP2 in Whole Pancreas}

UCP2 expression in whole pancreas was assessed via Western Blot. No significant difference was seen between the two groups (E-cig: $0.08 \pm 0.009 \mathrm{AU}$ vs. Control: $0.10 \pm 0.01 \mathrm{AU}$ ) $(p=0.179)$ (Figure 9). 


\section{CHAPTER 5: DISCUSSION}

The primary objective of this study was to determine if chronic exposure to E-cig vapor has a negative effect on overall glucose metabolism and pancreatic health in mice. The central hypothesis was that long-term exposure to E-cig vapor would result in reduced $\beta$-cell density, pancreatic islet area, and SIRT1 positive cells. We also hypothesized that this would lead to a reduced protein expression of SIRT1 and an increased amount of UCP2 in the pancreas. The primary findings in this thesis were that 8 months of E-cig exposure led to no significant changes in $\beta$ cell density or islet area when compared with control mice. Furthermore, 8 months of E-cig exposure did not result in a significant differences in total SIRT1(+) $\beta$-cells, SIRT1 protein, or increase in UCP2 protein in pancreas tissue. It did, however, reduce the density of SIRT1(+) $\beta$ cells within the islets of the pancreas.

Exposure to nicotine through regular cigarettes has been linked with insulin resistance (3, $4,5,6)$ and the development of $\operatorname{T2DM}(7,8,9,10,11,12)$. We proposed that exposure to E-cigs would create a similar effect on blood glucose based on the presence of nicotine in the vapor. After 6 months of exposure, resting blood glucose was not different between groups although there was a trend for higher values in the E-cig mice. After an acute exposure, fasting blood glucose levels in the E-cig mice were significantly higher than control. Although it is difficult to make general conclusions from this single time point on blood glucose measurements, it does suggest that acute exposure to E-cigs produced an exaggerated glucose response. These data are similar to those presented in other studies looking at nicotine $(84,85,86)$, but thus far only one other study has focused primarily on blood glucose as it pertains to E-cig exposures. This study also reported an impaired glucose response following E-cig exposure (89). 
To determine if glucose handling was also altered following chronic exposure to E-cigs, a two-hour OGTT was performed. No differences were observed between groups. We followed this by administering an OGTT following a 4-hour acute exposure. Again no differences were observed between groups. It is worth noting that we had a difficult time getting mice to fully consume the glucose pellet following the E-cig exposure. Therefore, we performed an IPGTT on a subset of mice because this had been shown to be a more reliable method for determining glucose tolerance (23). Results revealed a significantly increased area under the curve for the subset of E-cig animals tested. The general shapes of the curves were the same, but because glucose values in E-cig mice began at a higher fasting glucose level, they spiked higher and remained more hyperglycemic throughout the test when compared to the control animals. This is consistent with the literature stating that exposure to nicotine altars the glucose response profile (88). Xu et al (88) focused on nicotine's effect on insulin and found it to be in inhibitor of insulin release; however, no plasma insulin or HbAlc measurements were taken during our study, which limits the interpretation of our results. An insulin tolerance test was performed, but unforeseen circumstances within the test caused an early termination and no results. Still notable, however, was during that aborted test, E-cig mice did have higher glucose levels following an IP glucose injection and did not experience the extreme hypoglycemia seen within the control group. Narges et al (108) found hyperglycemia was induced after exposure to E-liquid, even with liquid containing no nicotine. This supports our trend that even without the acute presence of nitocine, glucose metabolism is altered due to chronic E-liquid exposure.

Other studies have linked nicotine directly to the dysfunction and destruction of pancreatic $\beta$-cells $(2,13)$. Because of these results, the focus of this thesis was primarily on potential changes to the pancreas as a result of E-cig exposure, which could lead to reduced 
insulin formation and secretion. Weir and Bonner-Weir (106) have described five stages of $\beta$-cell dysfunction as a result of obesity. Stage 1 is characterized by increased levels of plasma insulin, $\beta$-cell hypertrophy, and increased acute GSIS (106). Stage 2 is when truly normal glucose levels can no longer be maintained for any length of time and loss of acute GSIS (106). Stage 3 is unstable early decompensation (inability to properly regulate glucose and beginning stages of $\beta$ cell dysfunction), and stage 4 is stable decompensation. Finally, stage 5 is severe decompensation as full-blown diabetes (usually only T1DM) (106).

We hypothesized that an eight-month exposure to E-cig vapor would result in morphological differences in the pancreas. Decreases in both islet size and $\beta$-cell density within insulin-positive area were expected, however our results showed no difference in these variables between groups. These findings are not consistent with one report in the literature by El Golli et $a l$, who found that chronic exposure to smoke caused decreases in islet size and $\beta$-cell density (90). Islet area appeared to be larger in the E-cig mice but lacked statistical significance based on a small sample size and high variability of measure. Based on the Weir and Bonner-Weir principle, it is likely these E-cig animals were still in Stage 3 of dysfunction, or early decompensation, since they presented with higher fasting glucose but no real reduction in $\beta$-cell mass or density. Stage 3 has been reported to be extremely unstable and may be the critical step leading to T2DM (106). Some patients remain in this stage for excessive periods of time and continue having moderate blood glucose impairment while others progress rapidly into the fourth stage, marked by significant decreases in $\beta$-cell mass (106). Mice exposed to chronic E-cig vapor presented with significantly higher resting and stimulated blood glucose following 4 hours of exposure indicating either a reduced ability to secrete appropriate insulin levels or a reduced ability to respond to secreted insulin by peripheral tissues. 
Body weights were not different between E-cig and control mice throughout the study. Adipose tissue collected and weighed at the time of sacrifice were also not different between groups (data not shown). Because of this, we assumed that any differences in blood glucose did not arise from excessive adiposity or the associated pathologies from being overweight, but from the exposure itself. Nicotine is a known appetite inhibitor, whereas some sweeteners used in the e-liquid flavorings are known to increase appetite (109). El Golli et al tested the effects of Eliquid both with and without nicotine, and found increased glycemia in both groups (90). This supports our finding that the blood glucose is increased regardless of blood nicotine following exposure. More research is needed on this interaction (both in terms of nicotine and E-liquid, and E-liquid alone) to further understand the mechanisms at play and provide some insight into the differences seen in glucose metabolism without the weight gain typically associated with a T2DM phenotype. More research is needed in peripheral tissues (i.e. liver and skeletal muscle) to further characterize the potential effects that E-cig exposure may have on glucose handling.

SIRT1 has been shown to help regulate blood glucose by its ability to enhance glucose stimulated insulin release from the $\beta$-cells (49). It may do this in part, through its ability to downregulate UCP2. It has been postulated that SIRT1 decreases UCP2 levels in the $\beta$-cells by binding directly to the UCP2 promoter in order to silence it (23). Therefore, when SIRT1 is present in acceptable levels it allows energy coupling to proceed as normal. Reduction in UCP2 has been shown to restore normal insulin secretion (23). Results from the present study demonstrated that the total SIRT1 protein level of the pancreas was not different between groups while the density of SIRT1 positive $\beta$-cells where reduced following chronic E-cig exposure. Histochemical analysis of pancreatic sections revealed SIRT1 positive $\beta$-cells in the islets examined. Quantifying these images relied on some measure of subjectivity, which was partially 
mitigated by having only one person examine and count the images. Representative pictures are included (Figure 7C) indicating what was counted as a SIRT1(+) nucleus. The E-cig pancreas presented with less SIRT1(+) nuclei per islet area compared with controls. The significance here is likely due to the trending differences in both mean SIRT1(+) nuclei and islet area, with some of the variance accounted for by both measures, allowing $\operatorname{SIRT1}(+)$ density to reach significance. Reduced pancreatic SIRT1 has been shown to result in impairments in insulin secretion $(23,50)$ and increased UCP2 (23), which is what we saw to some degree. We found that UCP2 protein tended to decrease, although not significantly, in the E-cig mice. This could be due to running the analysis on whole pancreas tissue. We saw the differences in SIRT1 specifically within the islets of the pancreas, so this limits our ability to relate these two findings and could explain the lack of significance for the SIRT1 ELISA. Although the protein levels appeared to be slightly higher, the SIRT1(+) $\beta$-cell density was lower in E-cig mice when normalized to islet area. Again, the limited sample size analyzed is likely an important factor. Examining the protein levels in a greater number of animals may help better define the SIRT1 response to chronic E-cig exposure. If we had isolated islets in the beginning, we may have also seen significant differences in SIRT1.

Oxidative stress has been shown to blunt SIRT1's activity in the pancreas (107). The animals exposed to E-cig vapor were undergoing near constant oxidative stress to their lungs and other organ systems (110), which could have contributed to the overall dysfunction of the pancreas without overt histological pathologies or differences (91). The fact that we saw a slight increase in total pancreas SIRT1 but decreased islet SIRT1 could strengthen the argument that these exposed animals are in an early state of decompensation, where the decompensatory mechanism acts first in the $\beta$-cells assuming the mechanism for SIRT1 dysfunction is similar to 
that of the whole pancreas (an initial hypertrophy accompanied by adequate compensation followed by atrophy and decompensation).

\section{Limitations and Future Directives}

The most notable limitation in the study is the lack of breadth in terms of blood nicotine/blood glucose data. The glucose tolerance tests allow only a brief glimpse into what is actually occurring metabolically with these animals and the study would have greatly benefitted from regular glucose testing, beginning much earlier in the study and continuing at a regular interval until the conclusion of the exposures. With this data, it would be easier to interpret the effect that the E-cig had on glucose handling. Second, it would have been prudent to periodically measure blood insulin and the insulin response throughout the study. There was an attempt at an IP insulin tolerance test, but due to unforeseen circumstances the mice became excessively hypoglycemic and the test had to be aborted for the well being of the mice. Even though no usable data came of the test, the E-cig animals appeared less hypoglycemic than the others. Finally, regular, or at least semi-regular, testing of blood nicotine post smoke exposure would also be beneficial. Cotinine, a stable metabolite of nicotine, levels were assessed via urine samples but do not provide the same picture of the nicotine profile the animals were experiencing. Future studies should incorporate regular and more frequent testing of blood glucose, insulin, and nicotine, perhaps at the end of every week.

Another potential limitation is that when pancreas samples were taken, there was only one small section cut away from the entire tissue to be preserved for histology. During tissue cutting on the cryostat, there were serial cuts of the same area of tissue. Literature exists supporting the notion that different regions of the pancreas (i.e. ventral vs. dorsal regsions) have different densities of $\beta$-cells $(111,112,113)$. When portions were taken in our study, their 
locations were not recorded as adequate tissue had to be preserved for protein analysis. Taking more samples from different loci within the tissue might prove insightful, as different islets can be better isolated that way. This might be a more robust way to tease out differences in islet area and $\beta$-cell density.

Additionally, there was one animal within the chosen subset that brought down all averages for $\beta$-cell number, density, and islet area. When this one animal is removed, $\beta$-cell density and islet area become statistically significant, with density significantly decreased and area significantly increased. There is no reason to exclude this animal, but this speaks for the conclusion that an increased sample size would have accounted for this and allowed the averages to reach significance.

In order to more fully understand the full effect nicotine has on the pancreas, further research is needed that involves varying concentrations of nicotine. For our study, we used $18 \mathrm{mg} / \mathrm{mL}$, but E-liquid can be made with almost any nicotine concentration ranging from 0 $>50 \mathrm{mg} / \mathrm{mL}$. A study that looks at $0 \mathrm{mg} / \mathrm{mL}$ nicotine vs low nicotine content $(5-10 \mathrm{mg} / \mathrm{mL})$ high nicotine content $(18+\mathrm{mg} / \mathrm{mL})$ may prove more effective in understanding the role nicotine plays on the destruction of proper function in the pancreas. Looking at E-liquid with $0 \mathrm{mg} / \mathrm{mL}$ nicotine would allow a better look at what these flavorings specifically are doing to the body and how they may or may not be altering overall glucose metabolism.

In future studies, assessment of $\alpha$-cell morphology and glucagon protein content may also be of some benefit. Since there was significant glucose impairment but no apparent changes to $\beta$ cell morphology, it stands to reason that $\alpha$-cells may also play a role in the development of this impairment (85). One might expect to see hypertrophied $\alpha$-cells, as a direct result of constant stimulation from catecholamines in response to the nicotine dosage. This could possibly explain 
the changes in glucose metabolism despite not seeing significant differences in $\beta$-cell morphology.

A more in depth look at pancreas and muscle proteins may also help to tease out specific differences in content. There may also be some merit to examining muscle morphology for GLUT4 translocation to determine effectiveness of glucose uptake at the level of the skeletal muscle. Because SIRT1 regulates transcription of FoxO1, which is responsible for Akt phosphorylation, SIRT1 and GLUT4 are tightly related. Much more information is required to fully understand how SIRT1 works, not just in $\beta$-cells but as a whole body mechanism. Possible future studies could look into performing smoke/vapor exposures with SIRT1 knockouts and SIRT1 global overexpressers to see if they respond in the same hyperglycemic manner as both each other and control.

In conclusion, we found that chronic exposure to E-cig vapor significantly alters glucose metabolism in that fasting blood glucose and glucose response are both increased after an acute E-cig exposure. These animals are believed to be in a state of pancreatic decompensation due to lack of morphological differences but presence of hyperglycemia. We also showed that SIRT1 $(+) \beta$-cells decreased within the pancreatic islets. More differences may be teased out with a greater sample size. 


\section{FIGURE LEGENDS}

Figure 1A. Mouse body weights in (g) over the 8 month exposure. $\mathrm{N}=13$ for each group. All data are represented as a mean $\pm \mathrm{SE}$.

Figure 1B. Mouse body weights in (g) at 6 months of exposure. $\mathrm{N}=13$ for each group. All data are represented as a mean $\pm \mathrm{SE}$.

Figure 1C. Mouse body weights in (g) at 8 months of exposure. $\mathrm{N}=13$ for each group. All data are represented as a mean $\pm \mathrm{SE}$.

Figure 2A. Fasting blood glucose measurements taken on a weekend (48 hours post exposure). Animals were fasted 8 hours. $\mathrm{N}=6$ for each group. All data represented as a mean $\pm \mathrm{SE}$.

Figure 2B. Fasting blood glucose measurements taken after a typical 4-hour exposure period. Animals were fasted 8 hours. $\mathrm{N}=6$ for each group. All data represented as a mean $\pm \mathrm{SE}$.

Figure 2C. An oral glucose tolerance test was administered at $2 \mathrm{~g}$ glucose $/ \mathrm{kg}$ body mass after 8 hour fast (48-hours post exposure). $\mathrm{N}=6$ for each group. All data represented as a mean $\pm \mathrm{SE}$.

Figure 2D. An oral glucose tolerance test was administered at $2 \mathrm{~g}$ glucose $/ \mathrm{kg}$ body mass after 8 hour fast and a typical 4-hour exposure period. $\mathrm{N}=6$ for each group. All data represented as a mean $\pm \mathrm{SE}$.

Figure 3. Blood glucose measurements taken post 8-hour fast and a typical 4-hour exposure period at the 6-month exposure time point during IPGTT. $\mathrm{N}=4$ for each group. All data are represented as a mean $\pm \mathrm{SE} . \mathrm{P}=0.05$

Figure 4A. Intraperitoneal glucose tolerance test where glucose bolus was given at $2 \mathrm{~g}$ glucose/kg body mass after 8-hour fast and 4-hour smoking exposure. $\mathrm{N}=4$ for each group. All data are represented as a mean $\pm \mathrm{SE}$. 
Figure 4A. IPGTT curve with E-cig curve accounted for increased baseline measurements. $N=4$ for each group. All data are represented as a mean $\pm \mathrm{SE}$. $\mathrm{P}=0.05$.

Figure 4C. Peak blood glucose, corresponding to the highest blood glucose reading reached during the test, occurring at $15 \mathrm{~min} . \mathrm{N}=4$ for each group. All data represented as a mean $\pm \mathrm{SE}$. $\mathrm{P}<0.04$.

Figure 4D. Area under the glucose tolerance curve in arbitrary units squared. $N=4$ for each group. All data are represented as a mean $\pm \mathrm{SE} . \mathrm{P}<0.02$.

Figure 5A. Average $\beta$-cell number within insulin positive area. $N=6$ for each group. All data are represented as a mean $\pm \mathrm{SE}$.

Figure 5B. Average $\beta$-cell density [number of $\beta$-cells /islet (insulin positive area)]. $N=6$ for each group. All data are represented as a mean $\pm \mathrm{SE}$.

Figure 6A. Average islet (insulin positive) area. $\mathrm{N}=6$ for each group. All data are represented as a mean \pm SE.

Figure 6B. Representative image showing DAPI (blue) and insulin (red) stains.

Figure 7A. Representative image showing how SIRT $(+)$ nuclei were determined and counted (green nuclei within red insulin positive area).

Figure 7B. Average $\mathrm{SIRT}(+)$ nuclei contained in a single islet. $\mathrm{N}=6$ for each group. All data are represented as a mean $\pm \mathrm{SE}$.

Figure 7C. Average $\operatorname{SIRT}(+)$ density, number of $\operatorname{SIRT}(+)$ nuclei per islet area. $\mathrm{N}=6$ for each group. All data are represented as a mean $\pm \mathrm{SE}$. $\mathrm{P}=0.05$. 
Figure 8. SIRT1 protein concentration in whole pancreas tissue homogenate as determined by ELISA kit (Abcam). $\mathrm{N}=5$ for E-cig, $\mathrm{N}=9$ for control. All data are represented as a mean $\pm \mathrm{SE}$.

Figure 9. UCP2 protein concentration in whole pancreas tissue homogenate. $\mathrm{N}=8$ for each group. All data are represented as a mean $\pm \mathrm{SE}$. 


\section{FIGURES}

Figure 1A.

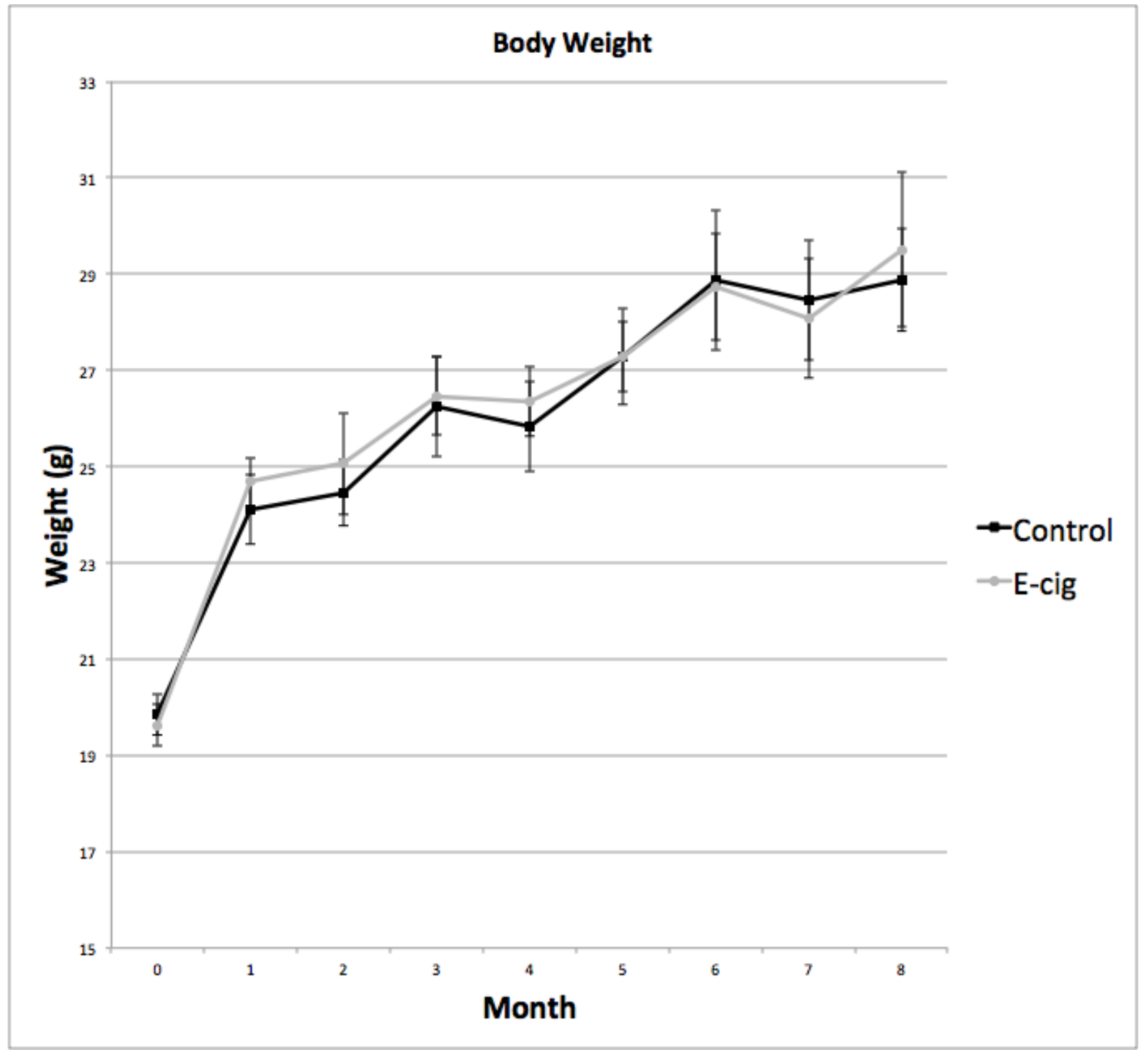


Figure 1B.

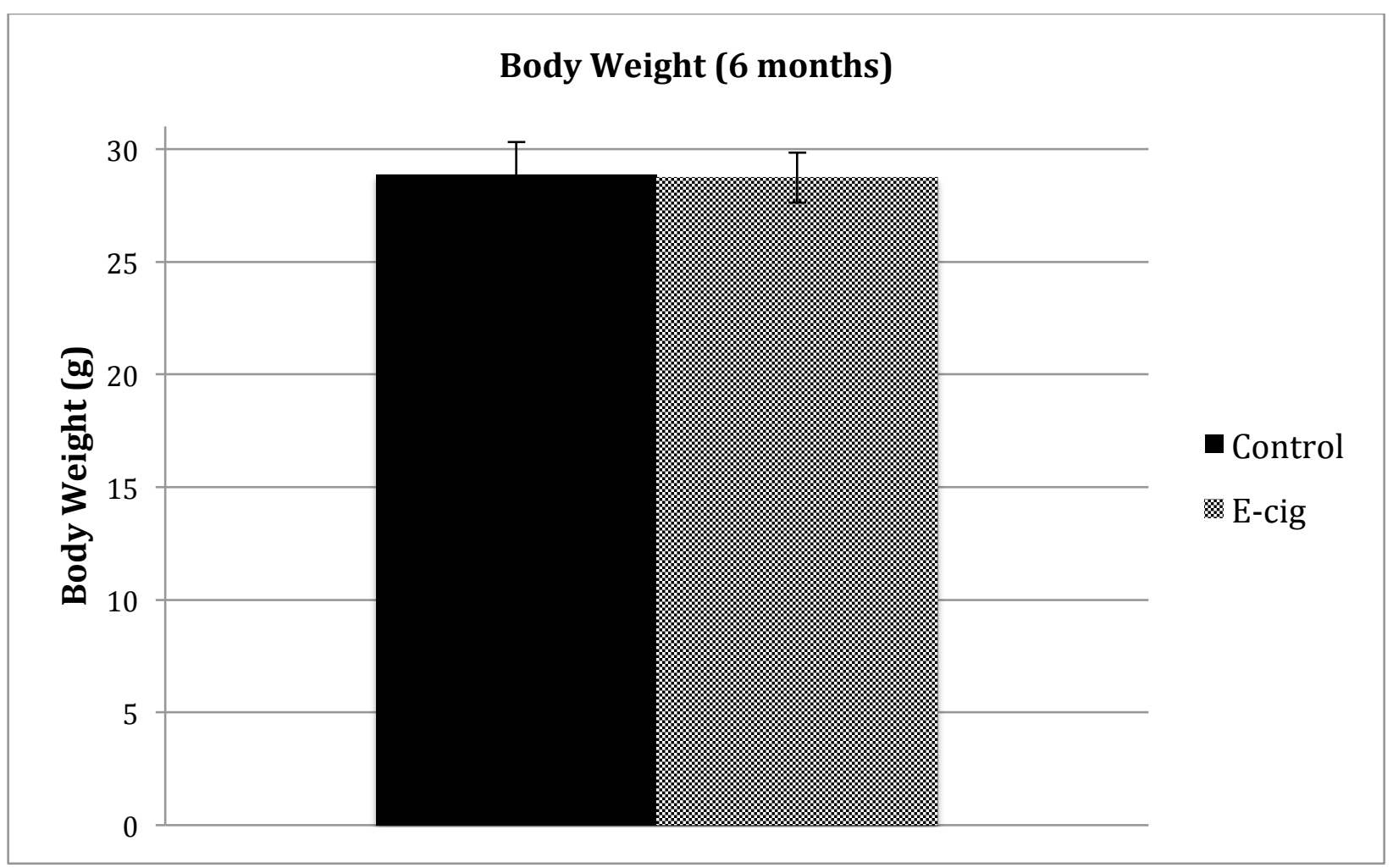


Figure 1C.

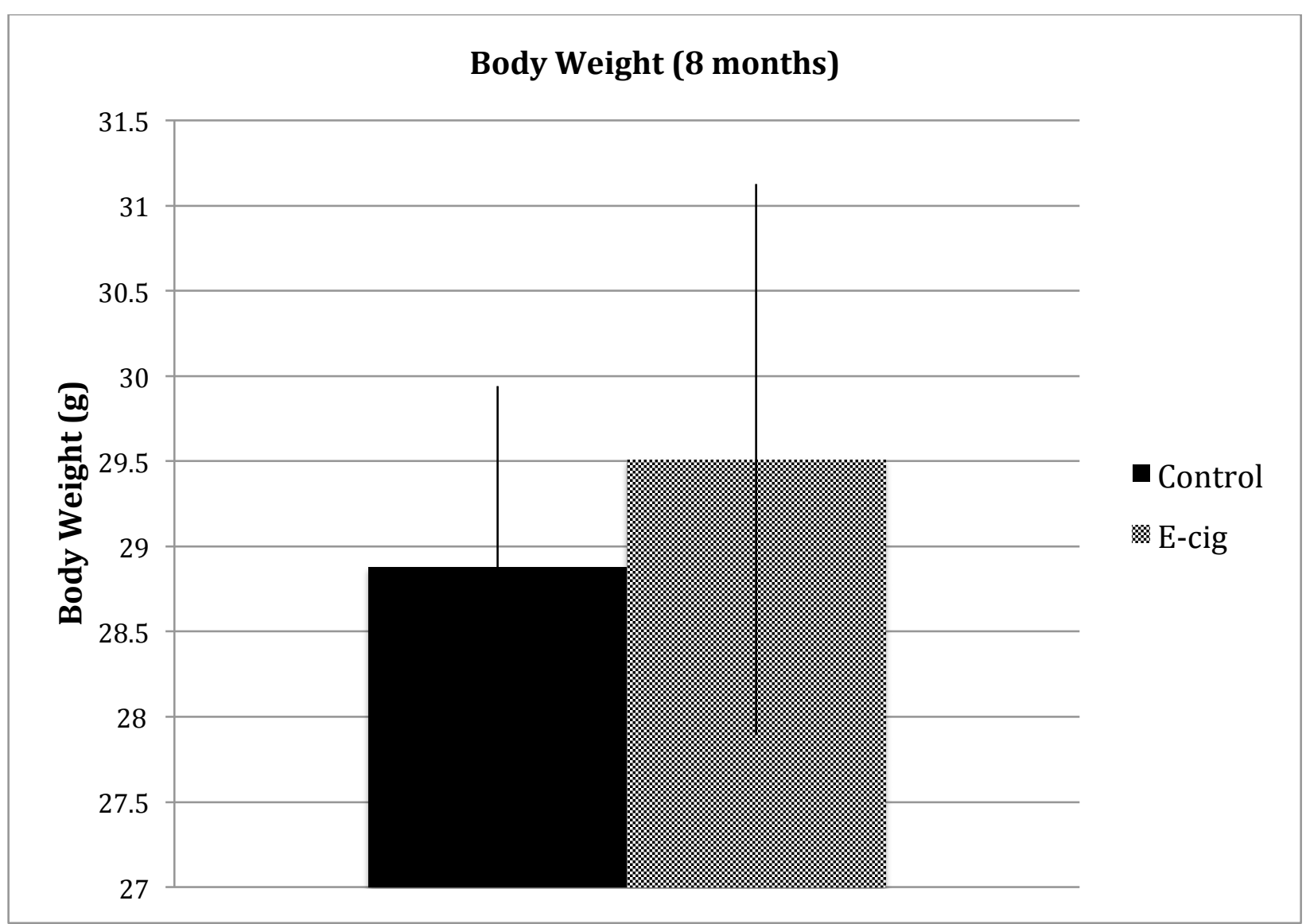


Figure 2A.

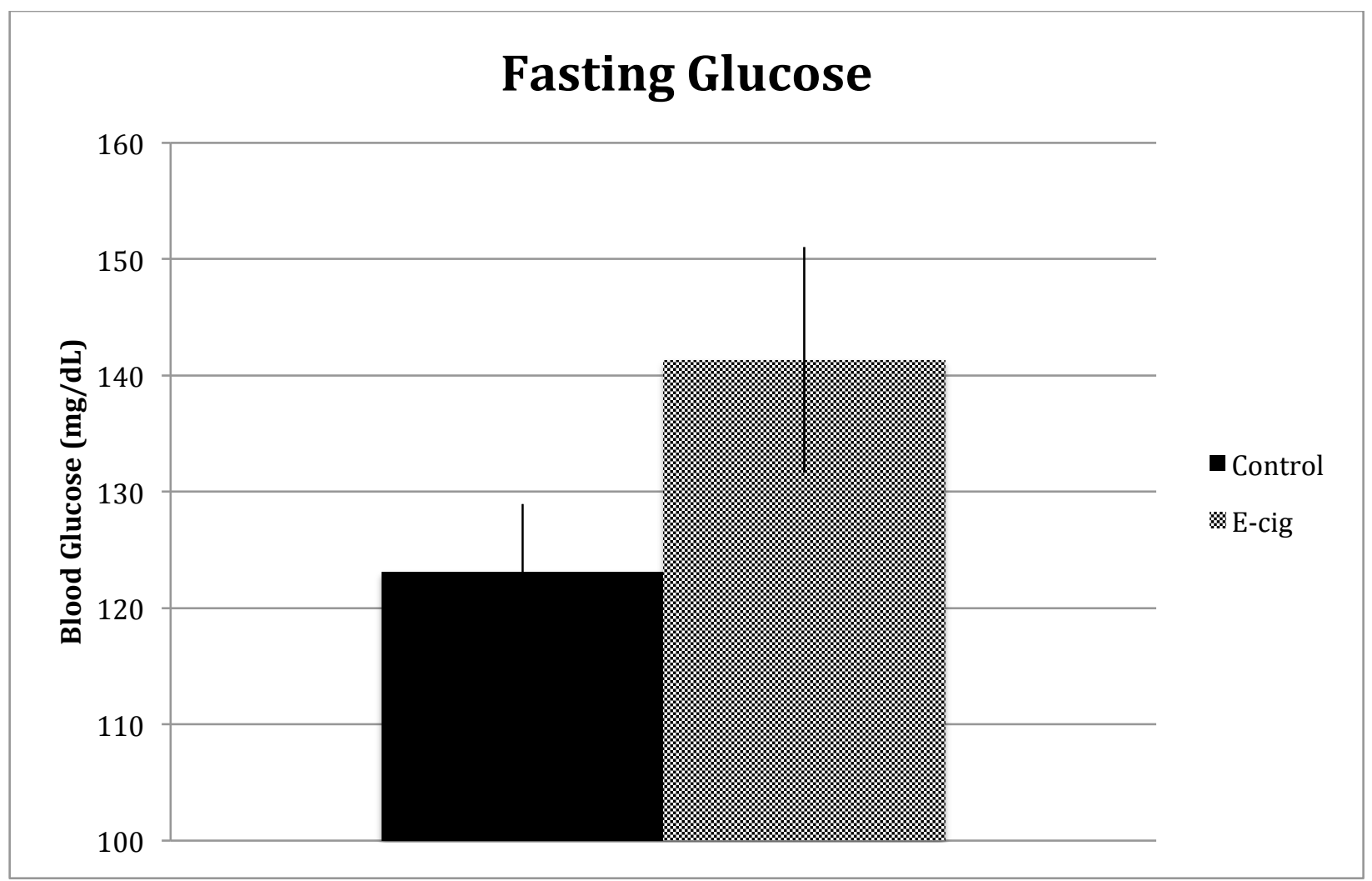


Figure 2B.

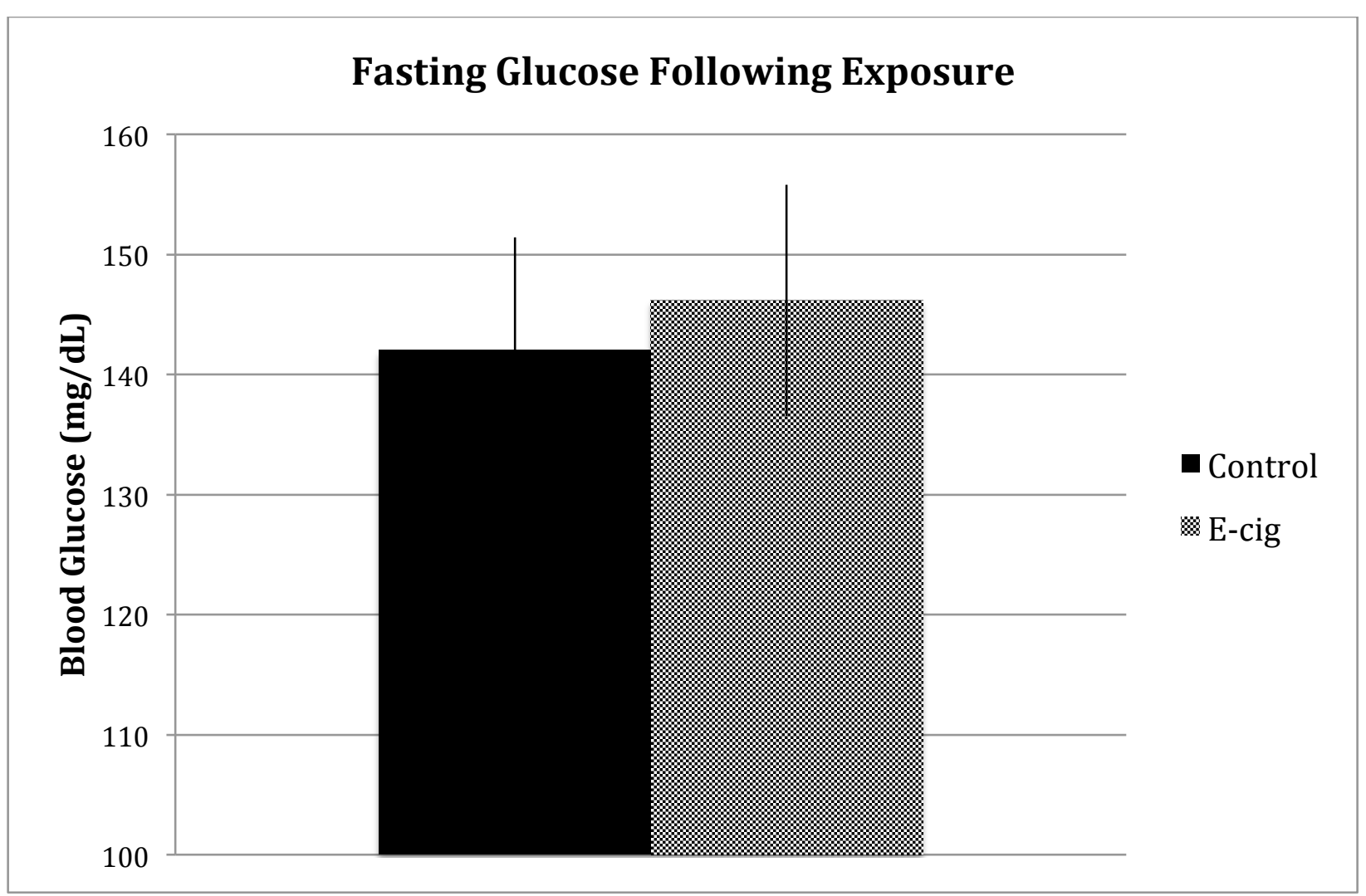


Figure 2C.

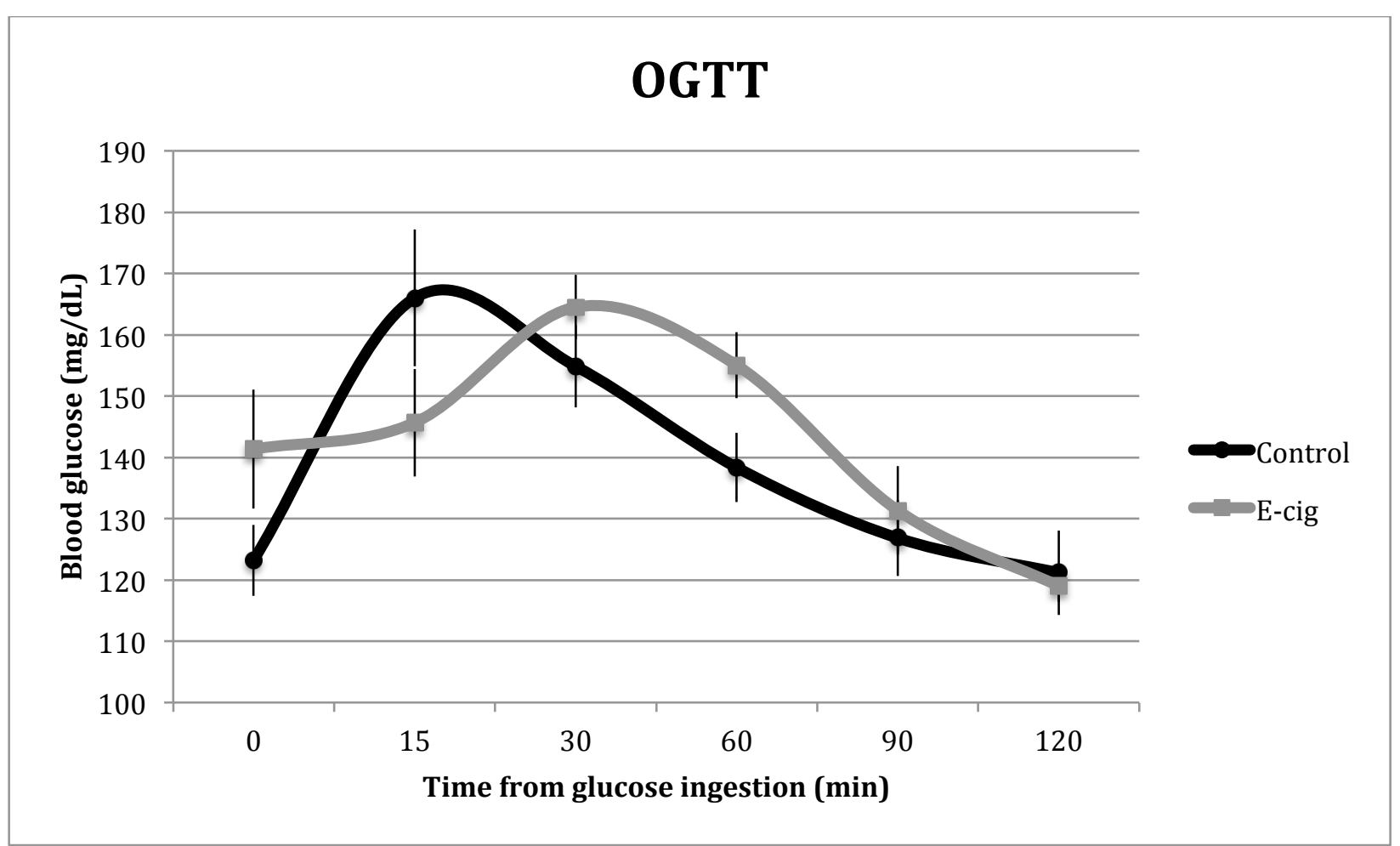


Figure 2D.

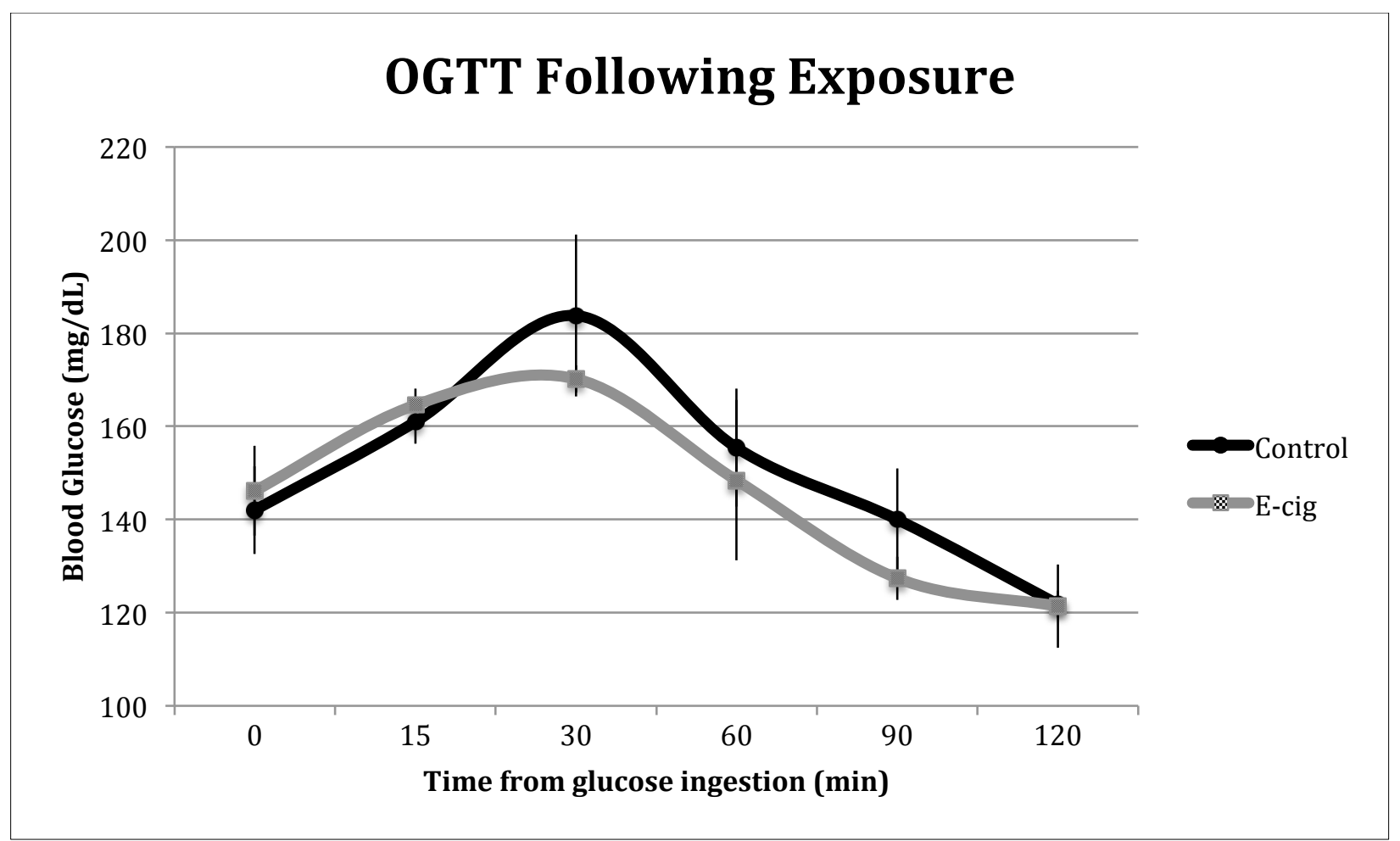


Figure 3.

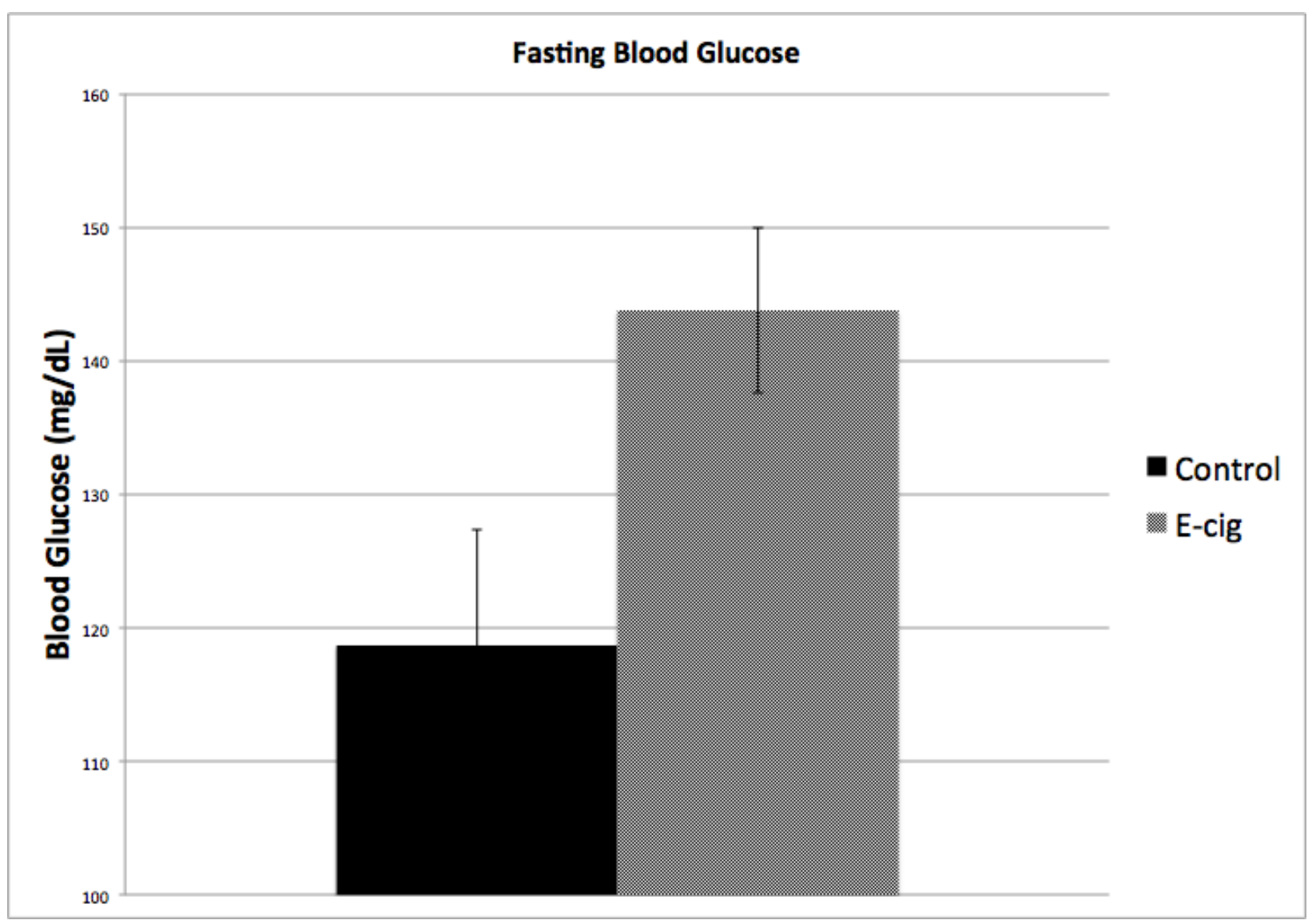


Figure 4A.

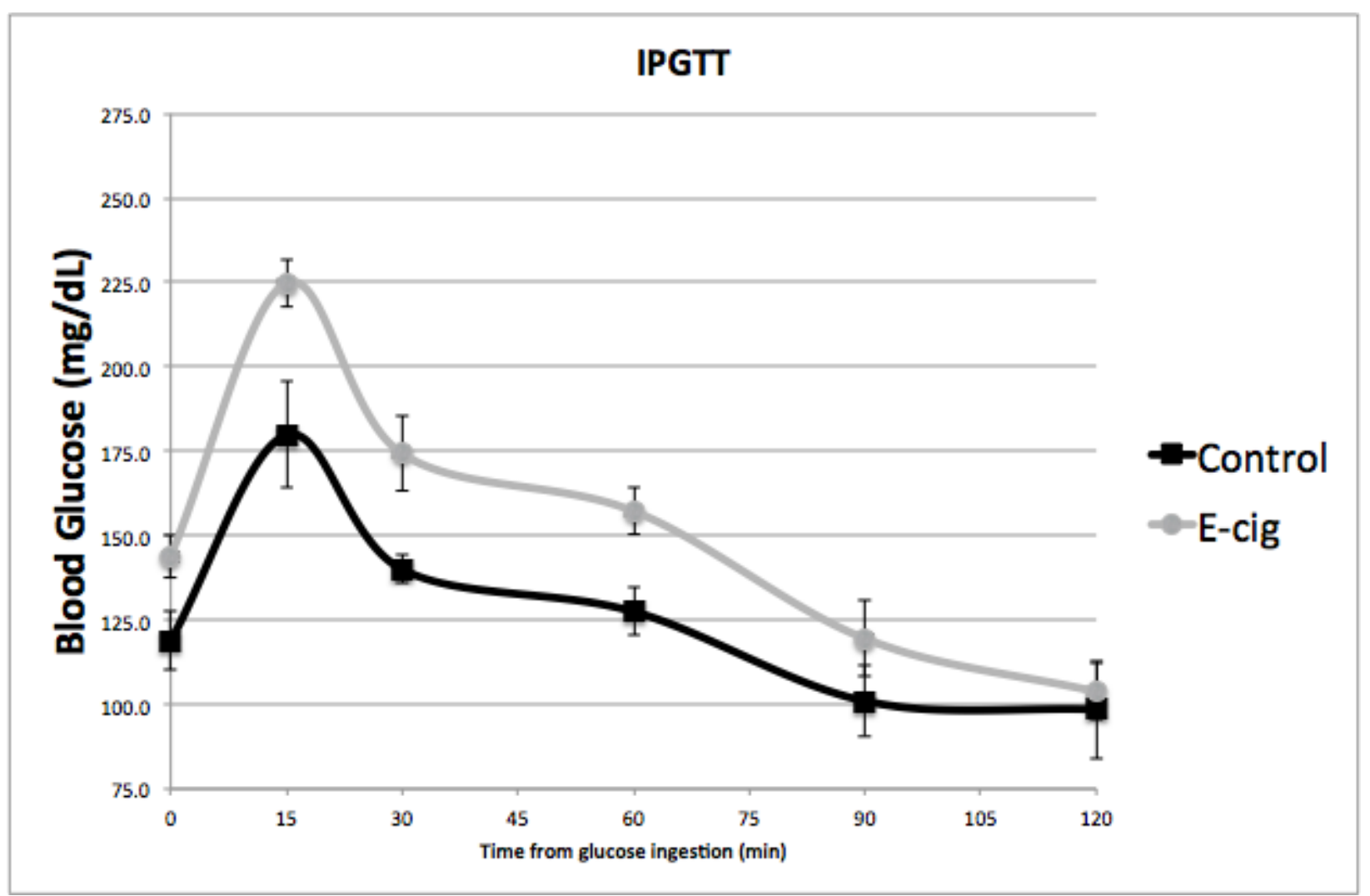


Figure 4B.

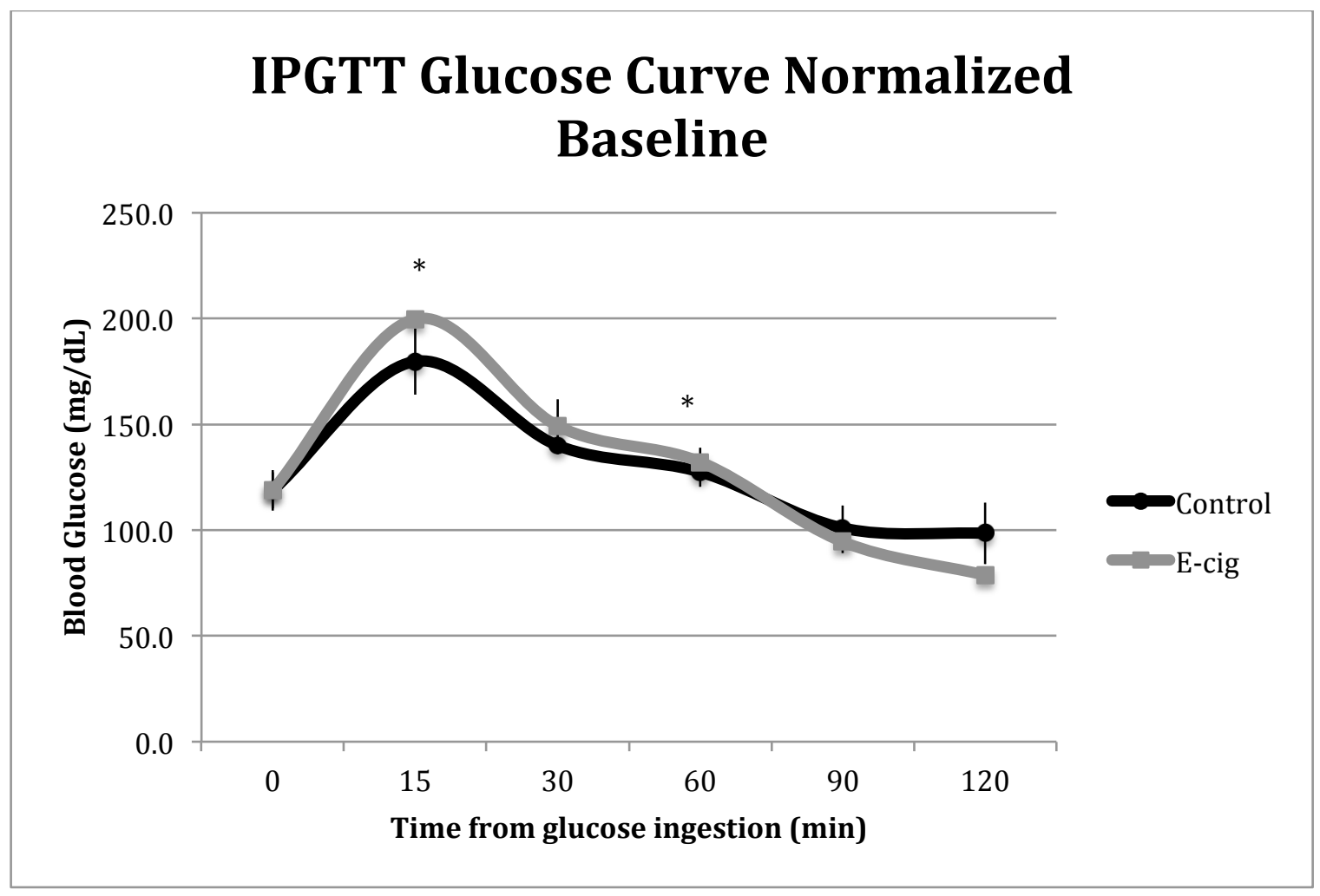


Figure 4C.

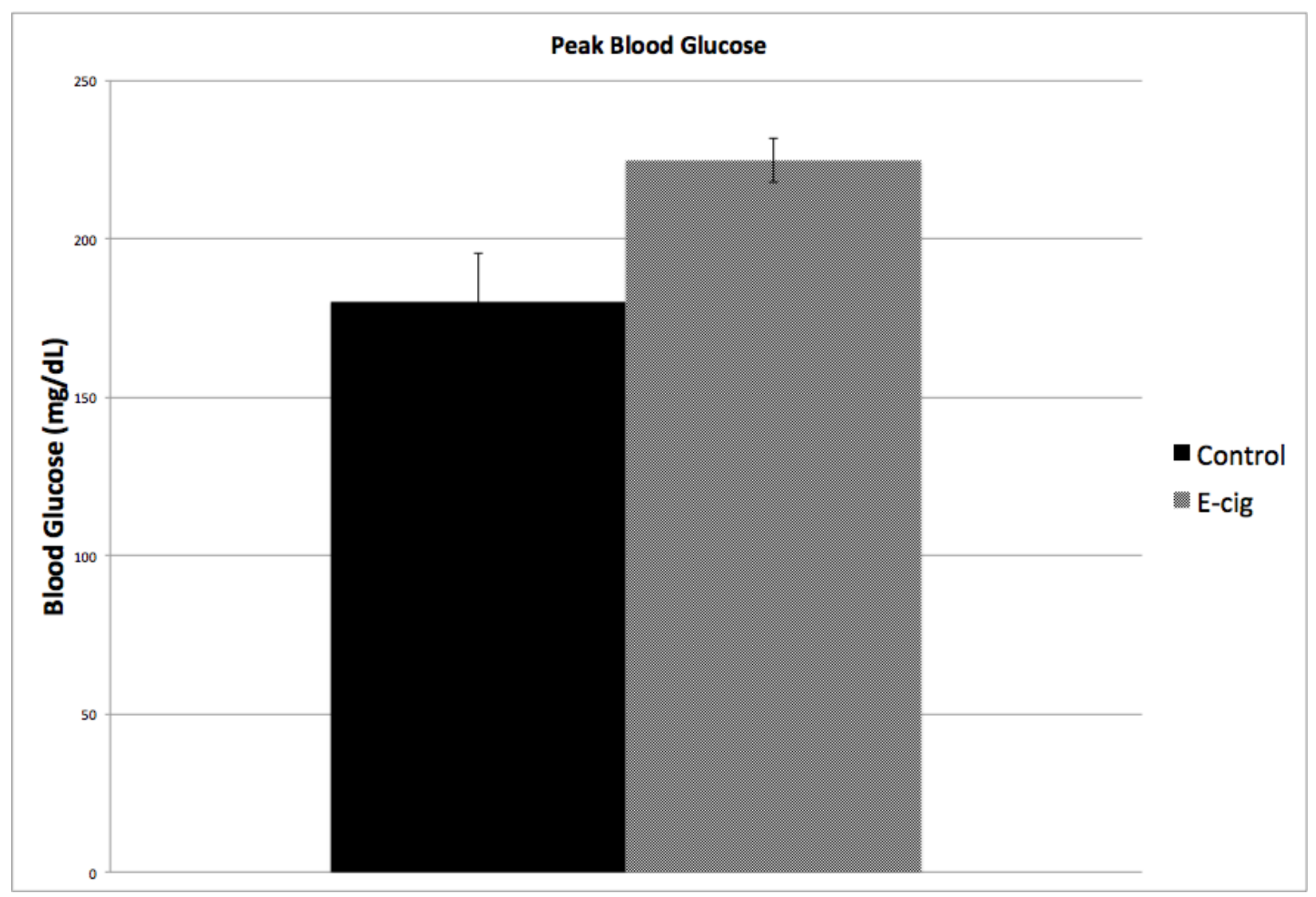


Figure 4D.

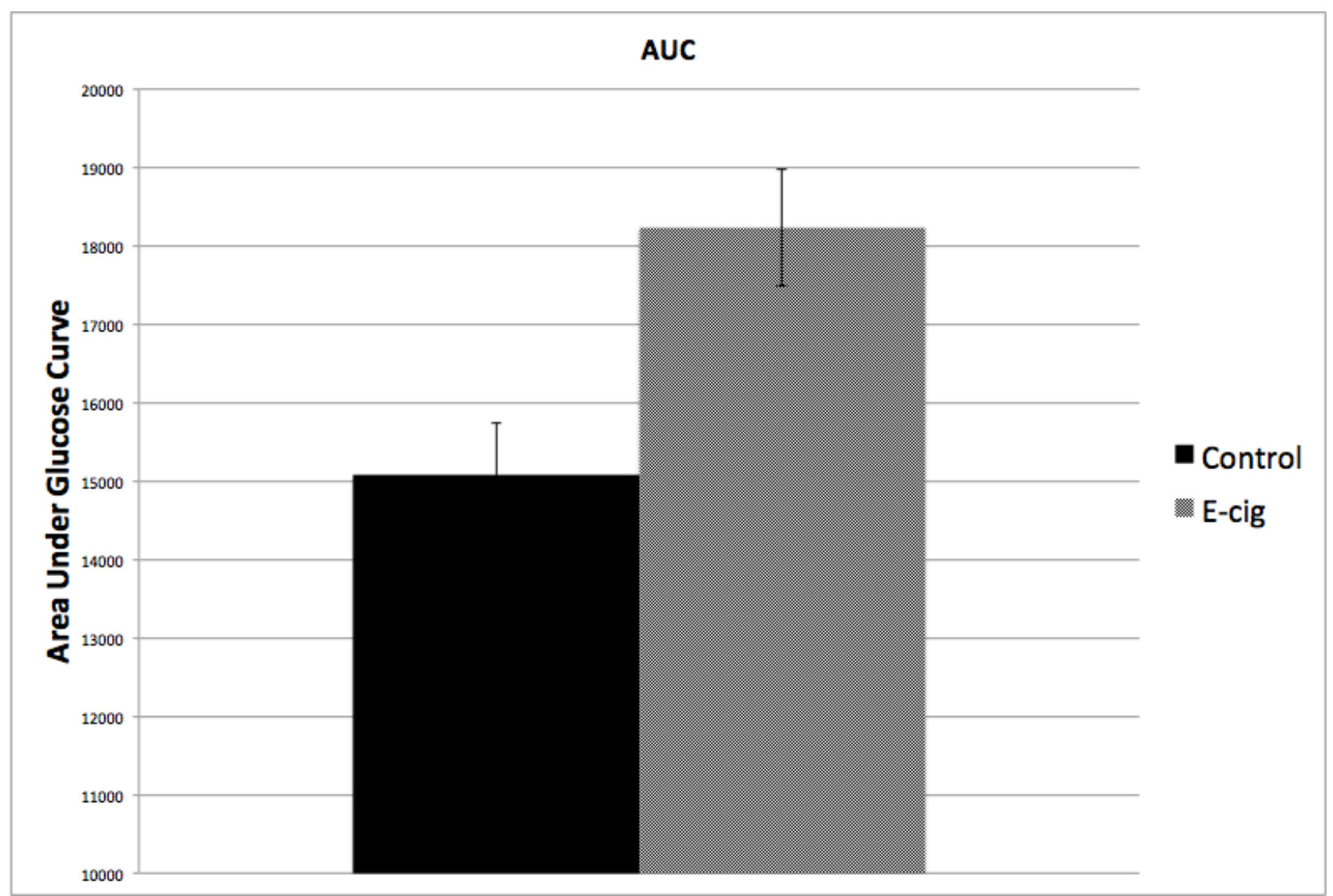


Figure 5A.

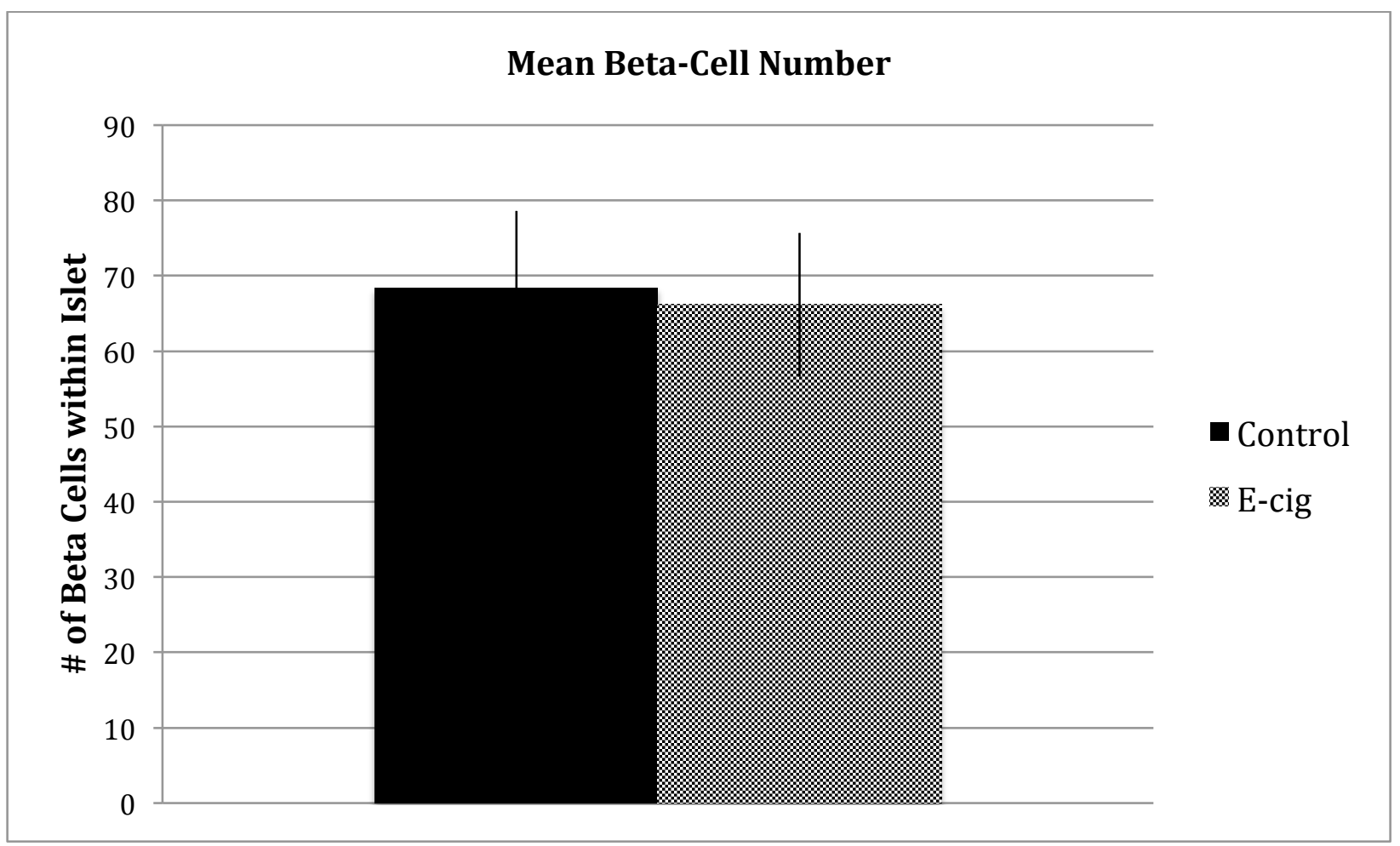


Figure 5B.

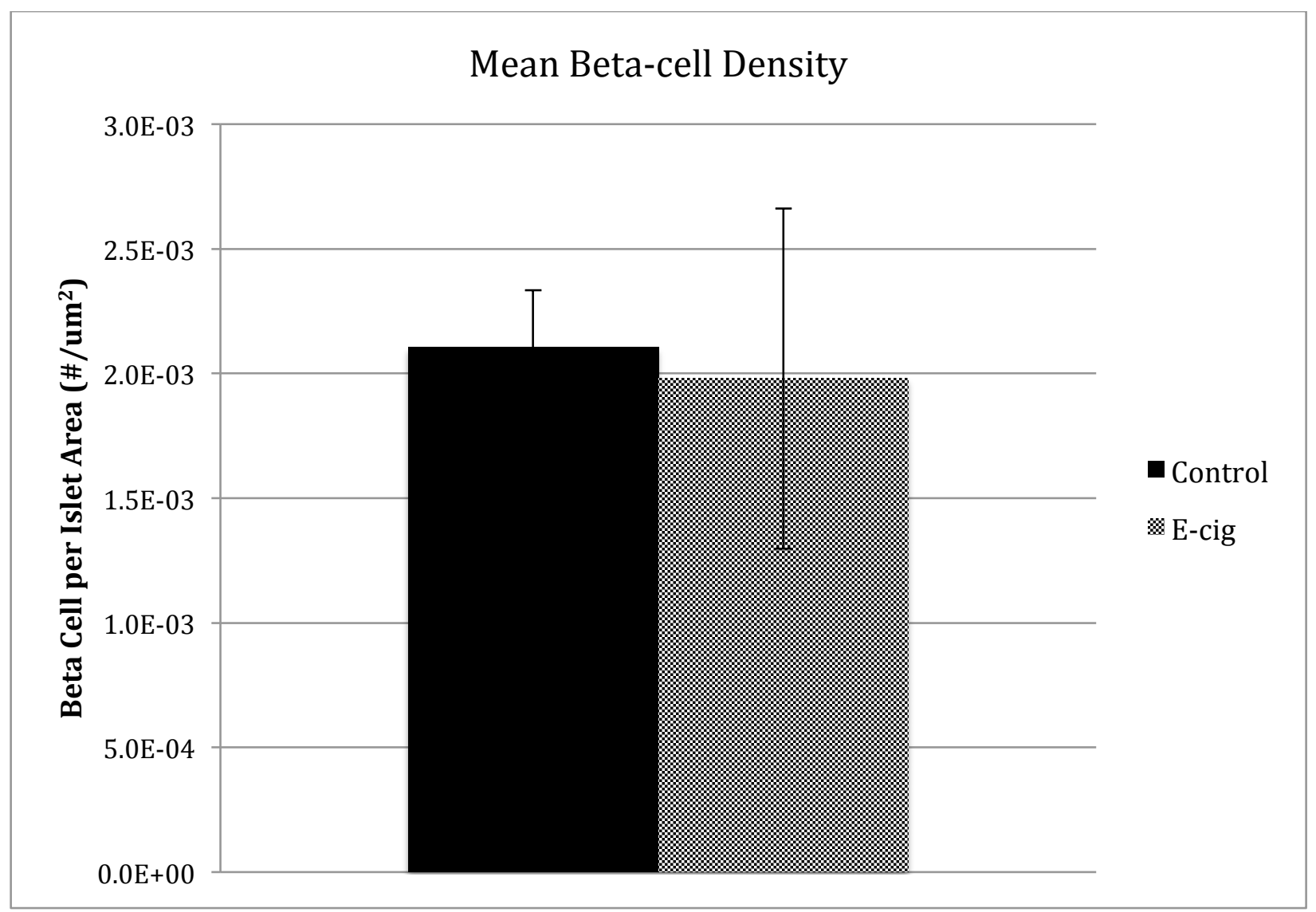


Figure 6A.

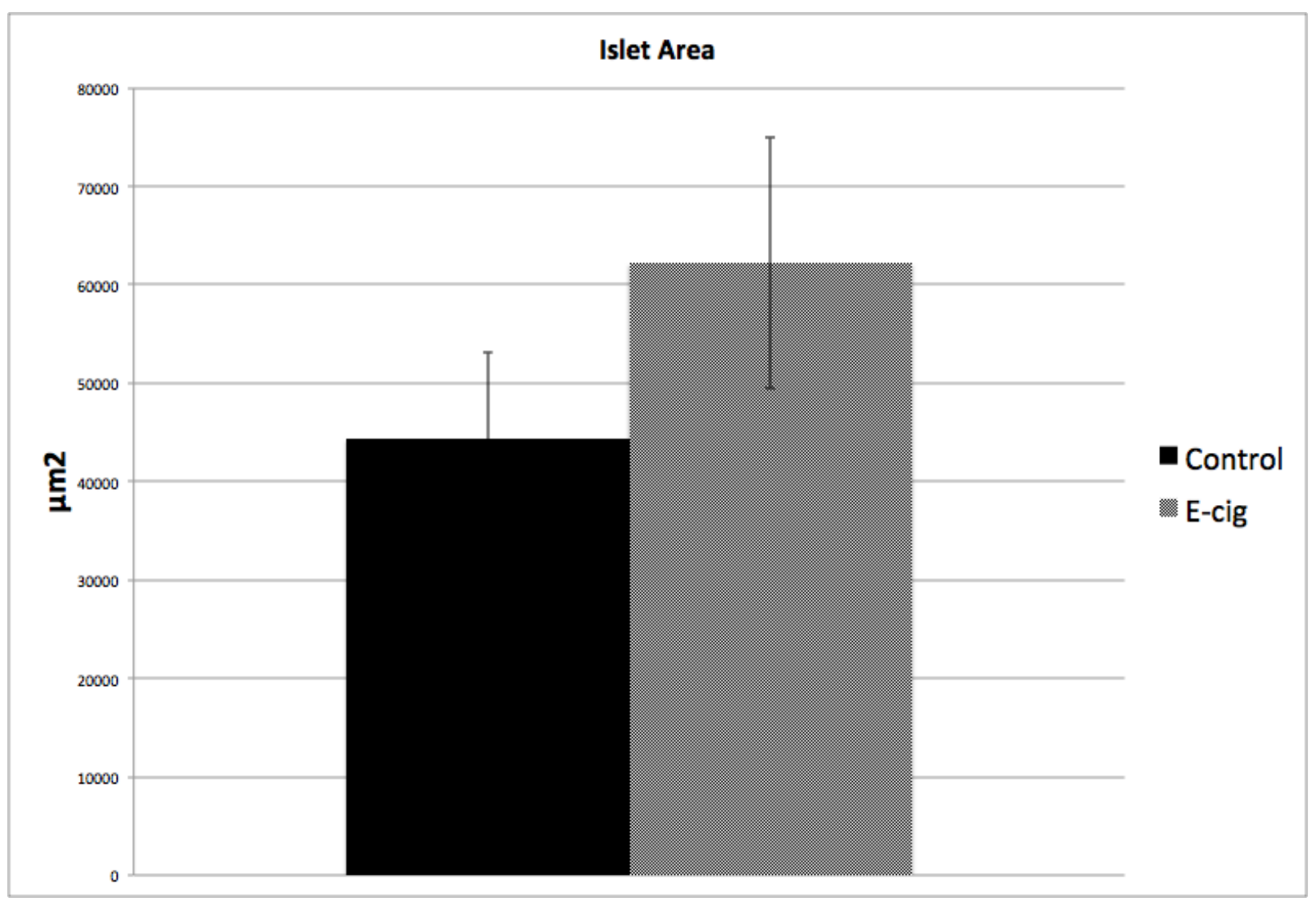


Figure 6B.

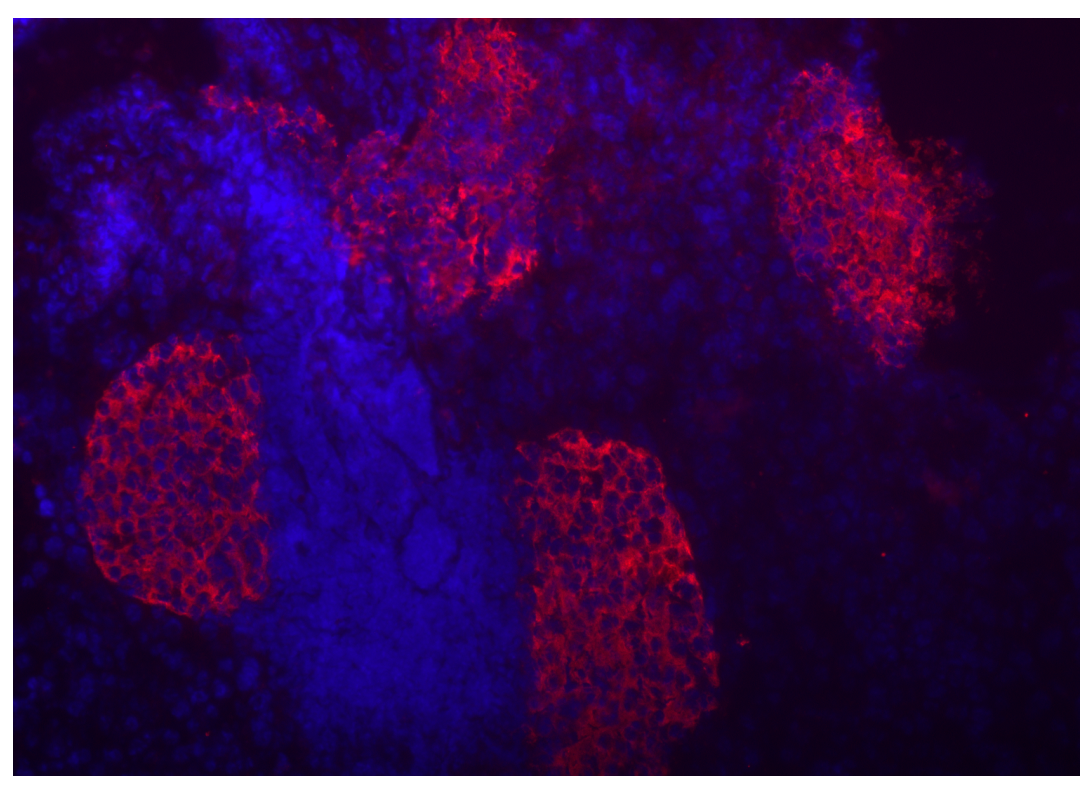


Figure 7A.

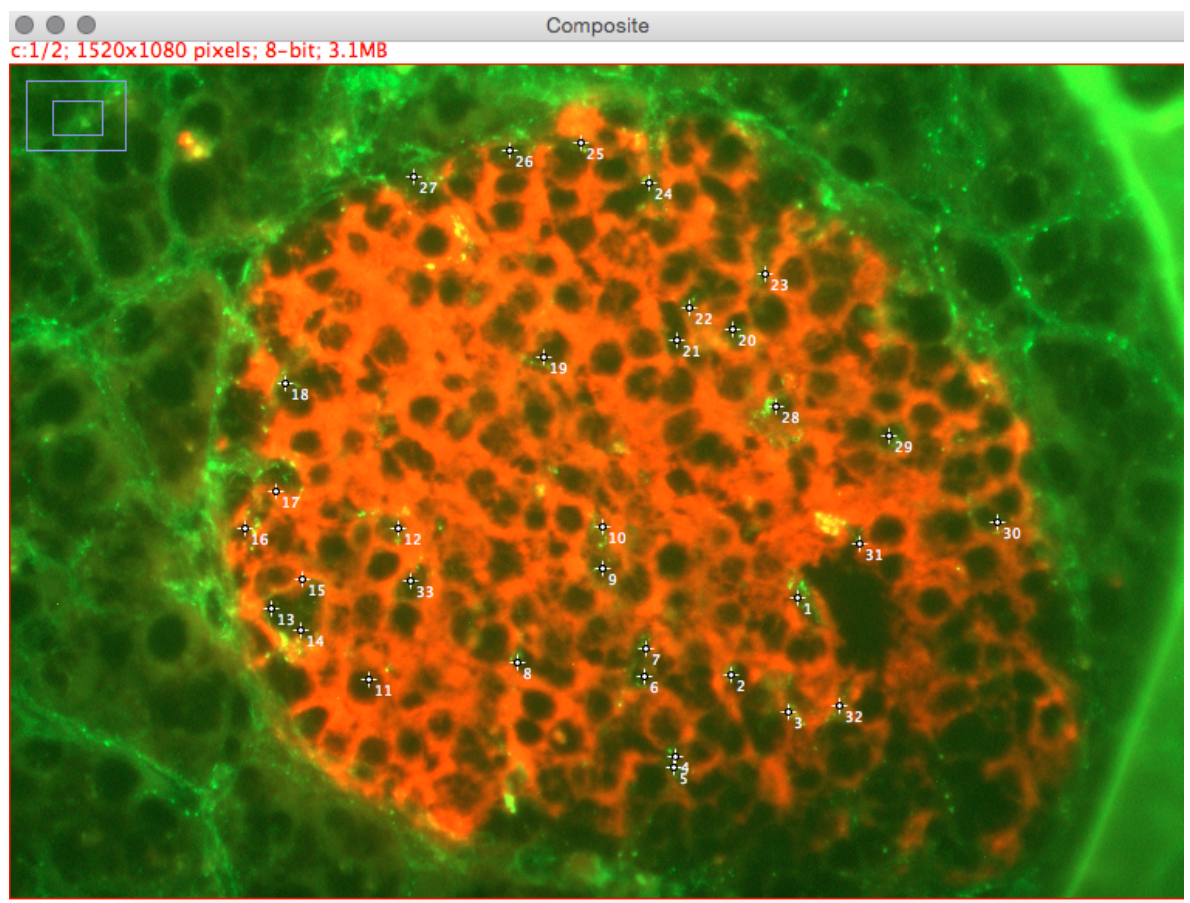


Figure 7B.

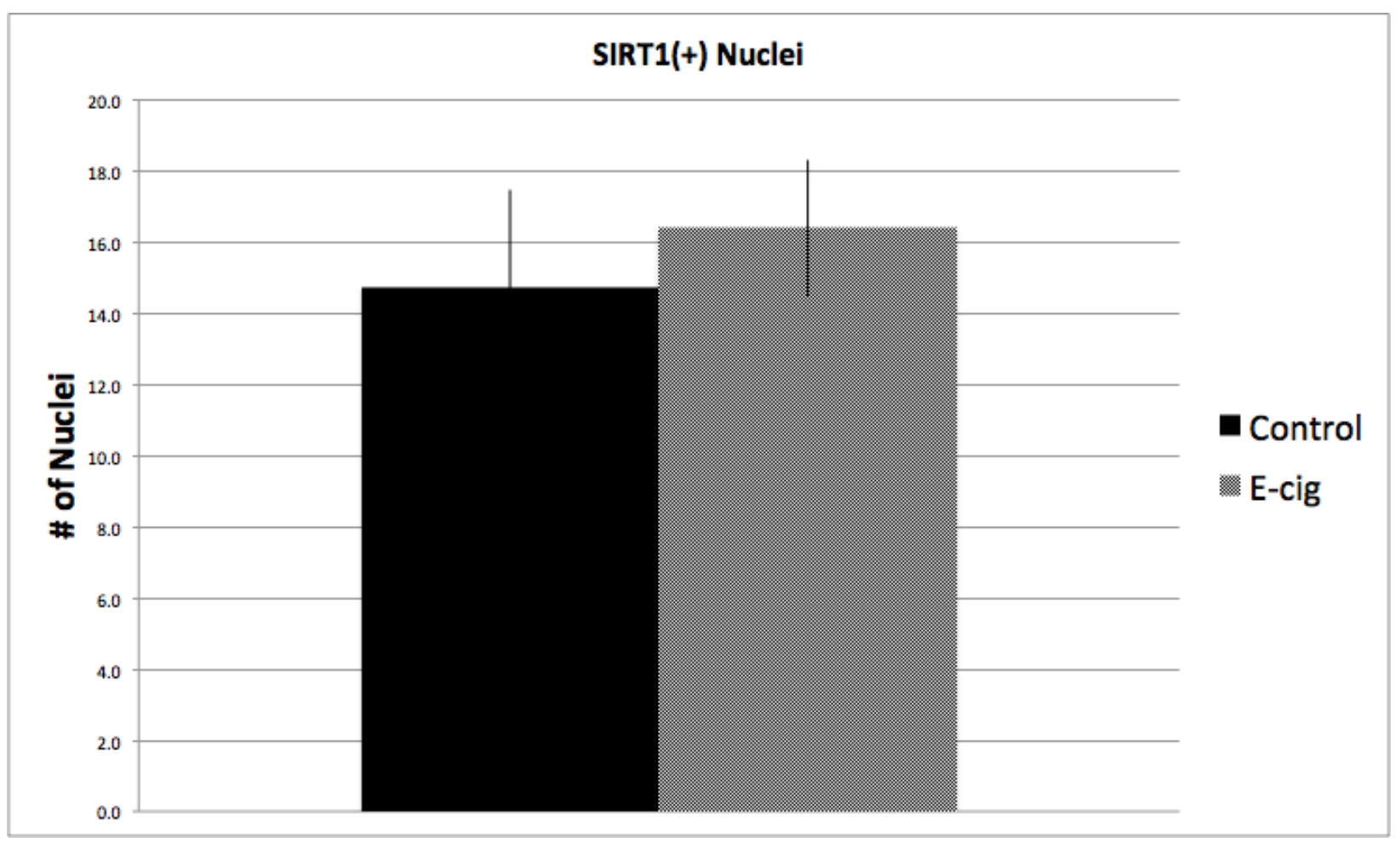


Figure 7C.

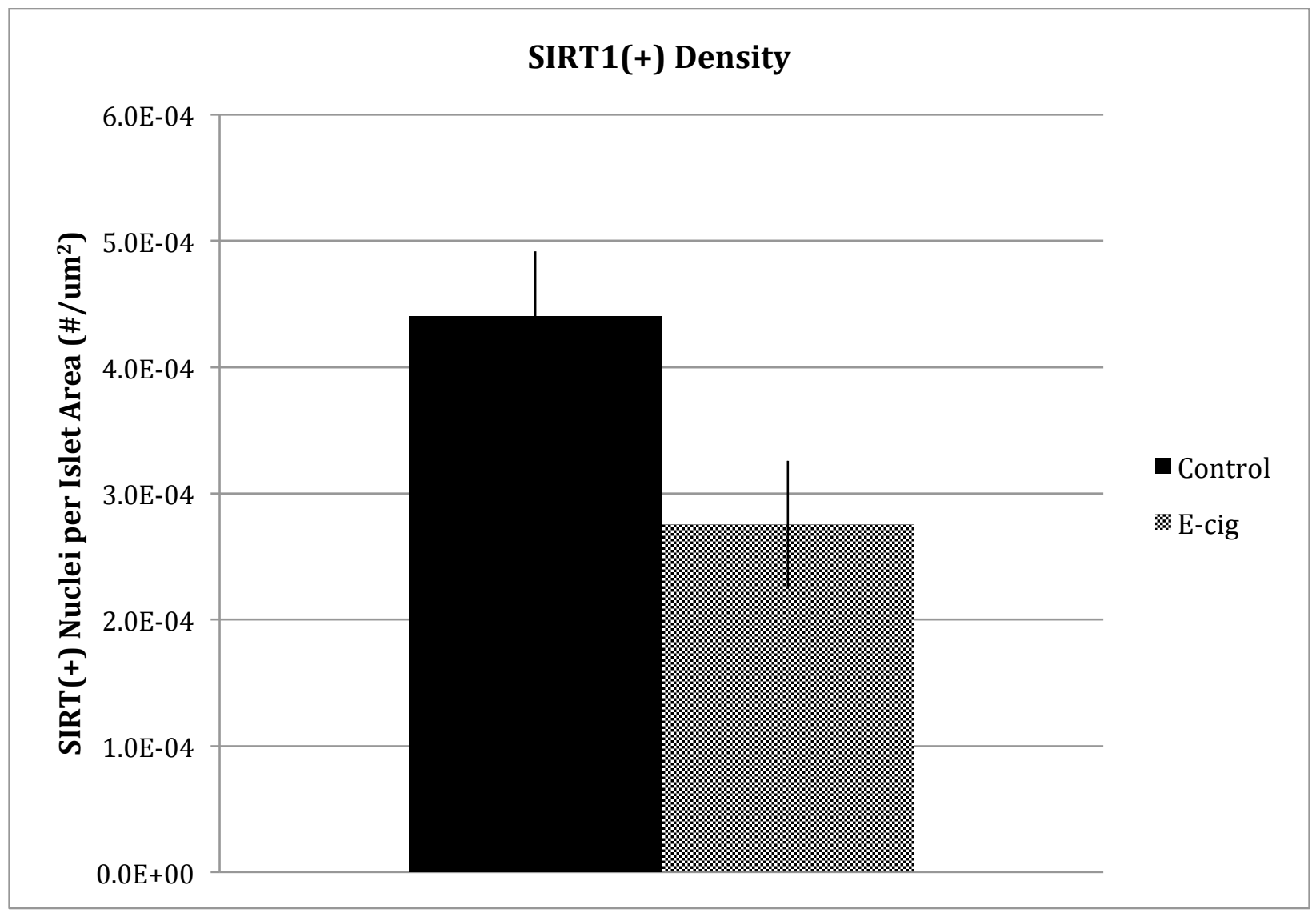


Figure 8.

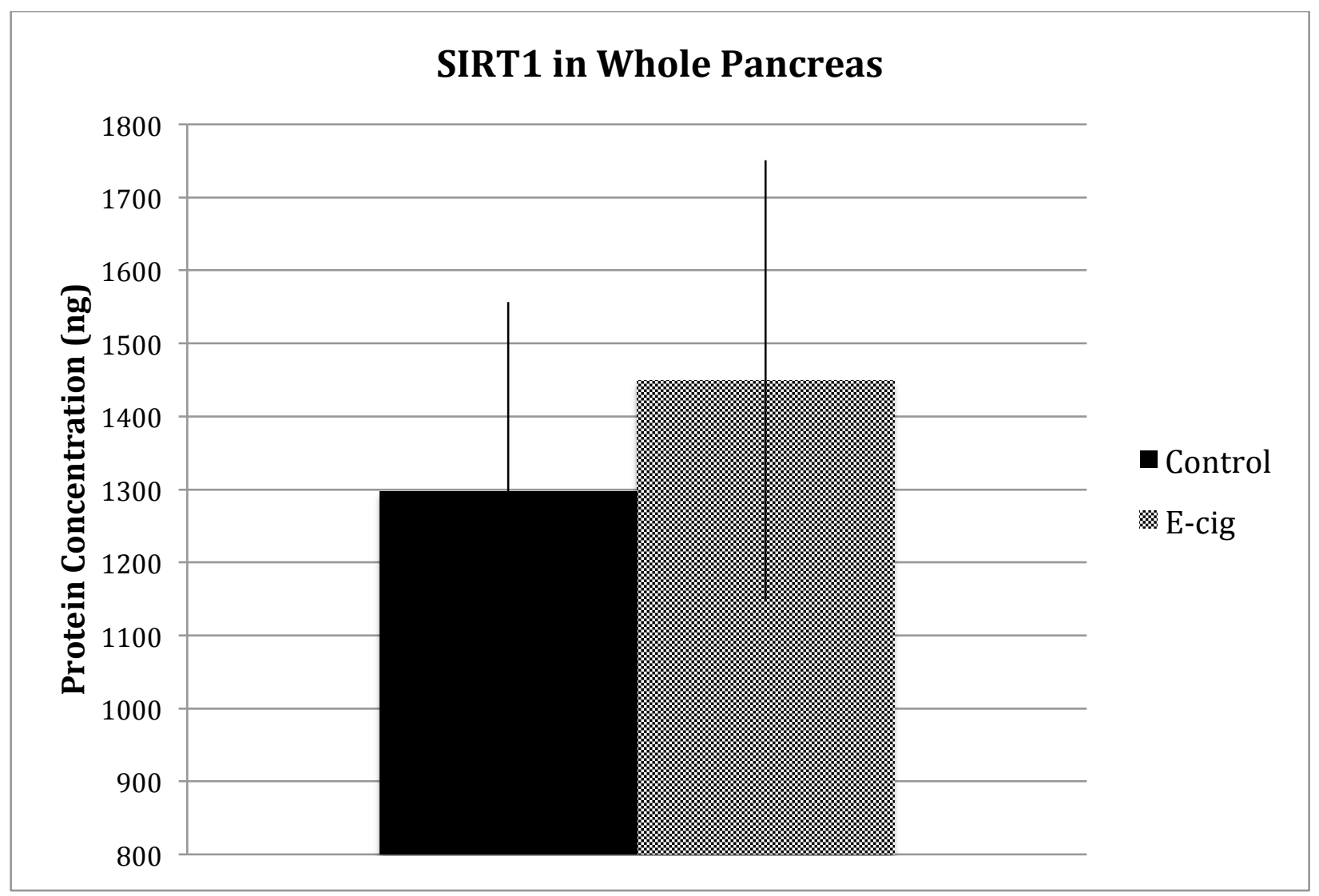


Figure 9.

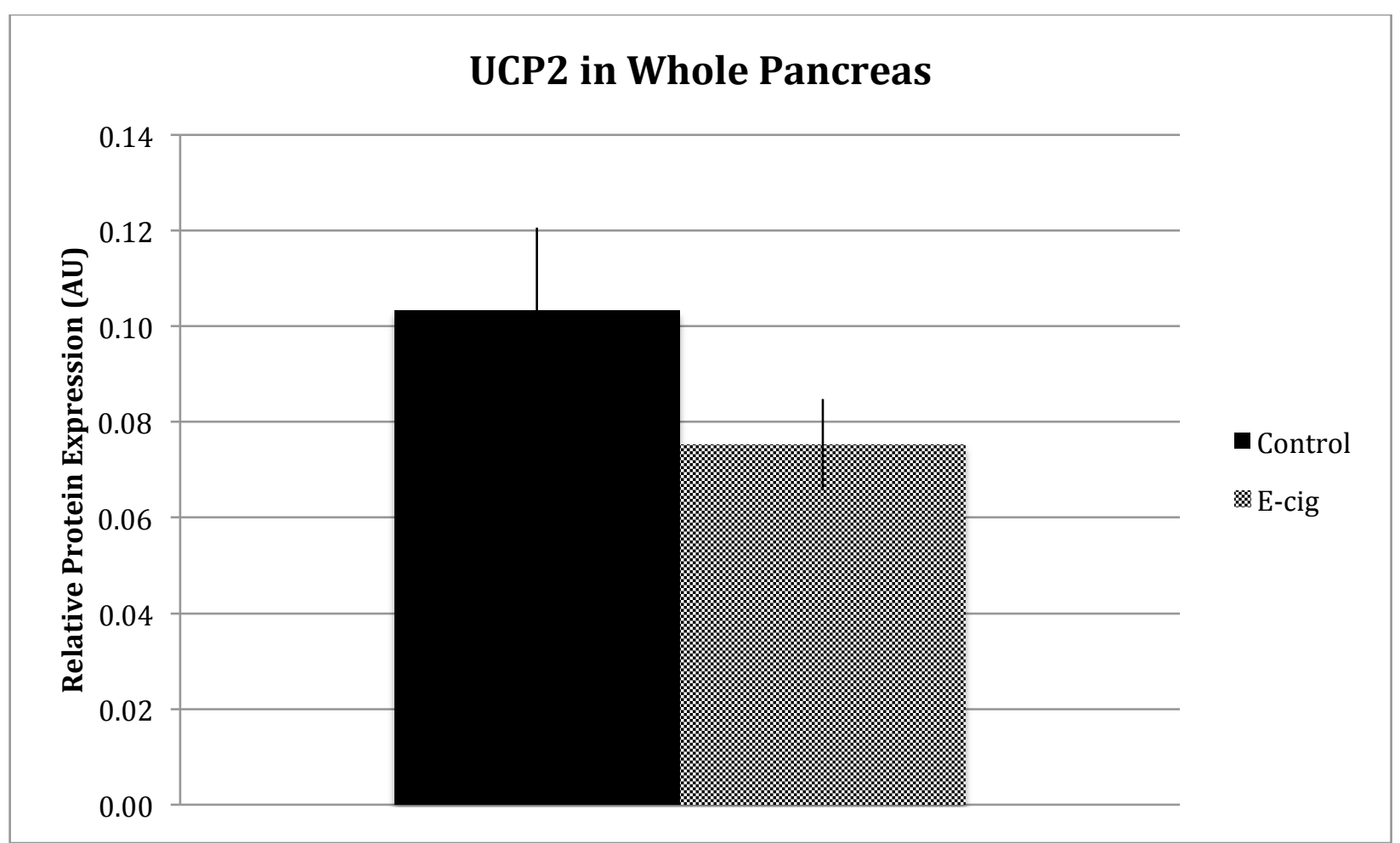

